\title{
LA PROHIBICIÓN DE PARTIDOS POLÍTICOS EN ALEMANIA. DEL NUEVO CRITERIO DE LA POTENCIALIDAD Y LA RECIENTE REFORMA CONSTITUCIONAL PARA LA NO FINANCIACIÓN DE FORMACIONES ANTIDEMOCRÁTICAS PERO CONSTITUCIONALES
}

PABLO FERNÁNDEZ DE CASADEVANTE MAYORDOMO 
SUMARIO

1. INTRODUCCIÓN. 2. EL DERECHO DE TODO SISTEMA DEMOCRÁTICO A DEFENDERSE. 2.1. APROXIMACIÓN TEÓRICA. 2.2. CLÁUSULAS EXPRESAS DE INTANGIBILIDAD Y CONTROL IDEOLÓGICO. 3. DEFENSA DE LA DEMOCRACIA Y PARTIDOS POLÍTICOS EN EL ORDENAMIENTO JURÍDICO ALEMÁN. 3.1. EL CONCEPTO ALEMÁN DE DEMOCRACIA MILITANTE. 3.2. RÉGIMEN JURÍDICO APLICABLE A LOS PARTIDOS POLÍTICOS ANTIDEMOCRÁTICOS. 3.2.1. MARCO CONSTITUCIONAL. 3.2.2. MARCO LEGISLATIVO BÁSICO. 4. LA ADAPTACIÓN JURISPRUDENCIAL ALEMANA AL TEST DE LA CONVENCIONALIDAD DEL TEDH: EL CASO DEL NPD. 4.1. EL CRITERIO DE LA NECESIDAD SEGÚN LA JURISPRUDENCIA DEL TEDH. 4.2. LA POTENCIALIDAD COMO SUSTITUTA DEL PRINCIPIO DE PROPORCIONALIDAD. 4.3. ANTIDEMOCRÁTICO PERO CONSTITUCIONAL. 5. PRINCIPALES OBSERVACIONES TRAS LA RECIENTE REFORMA CONSTITUCIONAL. 6. CONCLUSIONES. BIBLIOGRAFÍA. 


\title{
LA PROHIBICIÓN DE PARTIDOS POLÍTICOS EN ALEMANIA. DEL NUEVO CRITERIO DE LA POTENCIALIDAD Y LA RECIENTE REFORMA CONSTITUCIONAL PARA LA NO FINANCIACIÓN DE FORMACIONES ANTIDEMOCRÁTICAS PERO CONSTITUCIONALES
}

\author{
PABLO FERNÁNDEZ DE CASADEVANTE MAYORDOMO ${ }^{1}$
}

\section{INTRODUCCIÓN}

La importancia de los partidos políticos fue puesta de relieve hace ya décadas por Kelsen quien, con ocasión de su disyuntiva entre los conceptos de democracia ideal y real, definió dichas asociaciones como «uno de los elementos más destacados» de esta última ${ }^{2}$, pues es en ellas donde los afines en ideas se aglutinan con el objetivo de garantizarse una influencia eficaz en la marcha de la vida pública ${ }^{3}$. Transcurrido el tiempo, e inmersos como estamos en pleno siglo Xxi, observamos que dicha tesis goza de una vigencia plena, en la medida en que los partidos polí-

1 Profesor ayudante doctor - acreditado como contratado doctor por la ANECA —, Universidad Rey Juan Carlos. Facultad de Ciencias Jurídicas y Sociales. Paseo de los Artilleros s/n. 28032 Vicálvaro - Madrid. Email: pablo.fernandezdecasadevante@urjc.es. Aportación vinculada al proyecto de investigación «Consecuencias jurídicas de la secesión de entidades territoriales de un Estado, con especial referencia a las implicaciones en materia de derechos humanos. Enseñanzas para España», Referencia: DER2016-76312-P, Ministerio de Economía y Competitividad. Este trabajo ha sido posible, en buena medida, gracias a los recursos bibliográficos obtenidos durante las estancias de investigación realizadas en el Instituto Max Planck de Derecho Público Extranjero y Derecho Internacional Público (Heidelberg) y en el Instituto Max Planck de Derecho Penal e Internacional (Freiburg).

2 O lo que es lo mismo, del moderno Estado Constitucional.

3 KELSEN, H., Esencia y valor de la democracia, Labor, Barcelona, 1934, pp. 33 a 35. 
ticos han acabado por monopolizar las estructuras de los sistemas estatales regidos por el principio de democracia representativa ${ }^{4}$, «una vez que el mandato imperativo se revela como inservible» 5 .

Ahora bien, el derecho de asociación, que «habilita al sujeto para unirse establemente a otros para la consecución de fines legales» ${ }^{6}$, dista mucho de ser absoluto, extremo que queda corroborado, tanto por los textos constitucionales de nuestro derecho comparado más cercano como por los principales tratados internacionales ratificados en la materia, Convenio Europeo de Derechos Humanos - en adelante, $\mathrm{CEDH}$ - a la cabeza. En lo que aquí interesa, resulta obligado aludir también a la vasta doctrina dictada por el Tribunal Europeo de Derechos Humanos - TEDH en lo sucesivo- , de cara a avalar o rechazar medidas estatales contra determinados partidos políticos.

Teniendo en cuenta dicha profusión, podría pensarse que la cuestión relativa a la prohibición de fuerzas políticas ha dejado de gozar de interés jurídico. Nada más lejos de la realidad. La crisis económica, de valores y los numerosos puntos de inestabilidad político-constitucional existentes actualmente en Europa, han contribuido a la formación de un caldo de cultivo idóneo para los partidos políticos de corte nacionalista, populista, extremista y/o intolerante con determinados grupos sociales, cuando no con el propio sistema. Ejemplo de lo anterior es lo sucedido durante los últimos años en Alemania, país que está siendo testigo de un preocupante resurgir de la ultra derecha, consolidándose dicho fenómeno tras las elecciones federales celebradas el pasado 24 de septiembre de 2017 y la entrada en el Bundestag por parte de la formación Alternativa para Alemania o Alternative für Deutschland -en adelante AfD-.

Este último hecho ha constituido, sin lugar a dudas, un factor importante a la hora de decidirnos por abordar el estudio del régimen jurídico aplicable a los partidos antidemocráticos en el país germano. Los demás se remontan a los meses anteriores a dichos comicios, tiempo durante el cual se produjeron dos acontecimientos que influirán de manera indudable en la solución futura a dispensar a formaciones políticas antidemocráticas. Nos referimos, en primer lugar, al giro jurisprudencial adoptado por el Tribunal Constitucional, en su sentencia de 17 de enero de 2017, con res-

4 En esta línea, FERNÁNDEZ SARASOLA, I., «Idea de partido y sistema de partidos en el constitucionalismo histórico español», en Teoría y Realidad Constitucional, núm. 7, 1. ${ }^{\circ}$ semestre, 2001, p. 217. Léase igualmente a PRESNO LINERA, M. A., Los partidos y las distorsiones jurídicas de la democracia, Ariel, Barcelona, 2000; y a MORLOK, M., "La regulación jurídica de la financiación de los partidos en Alemania», en Teoría y Realidad Constitucional, núm. 6, $2 .^{\circ}$ semestre 2000 , p. 45.

5 VIDAL, C., «El derecho de participación política y la representación», en Revista Facultad de Derecho y Ciencias Políticas, N. ${ }^{\circ}$ 96, 1996, p. 85.

${ }^{6}$ GÓMEZ SÁNCHEZ, Y., «El derecho de reunión y asociación», en Rovira Viñas, A. (coord.) Gobernanza democrática, Marcial Pons, Madrid, 2013, p. 133. Más en DE ESTEBAN, J., y GONZÁLEZTREVIJANO, P. J., Tratado de Derecho Constitucional II, Universidad Complutense de Madrid, Madrid, 2004 , pp. 212 a 217. 
pecto al último caso en que se produjo la exclusión de un partido en el país —el KPD, en 1956-; y en segundo término, a la reforma constitucional —en vigor desde el 7 julio de 2017 — obrada para introducir en la Ley Fundamental de Bonn la posibilidad de excluir de la financiación pública a los partidos que, persiguiendo objetivos antidemocráticos — verfassungsfeindliche Ziele —, no sean declarados inconstitucionales al carecer de potencial para alcanzarlos.

Procedemos pues al análisis de dichas cuestiones, no sin antes proporcionar unas nociones jurídicas básicas que faciliten al lector el entendimiento y la formación de una opinión crítica al respecto.

\section{EL DERECHO DE TODO SISTEMA DEMOCRÁTICO A DEFENDERSE}

\subsection{Aproximación teórica}

Consistiendo la democracia en un régimen político ${ }^{7}$ basado en un sistema de diálogos — tal y como nos recuerda $\mathrm{Vedel}^{8}$ —, lo primero que cabe preguntarse es si en él tiene cabida la defensa de cualquier idea, incluso la de aquellas que se oponen al régimen político establecido.

Pues bien, para tratar de dar respuesta a esta cuestión, Lucas Verdú realiza un exhaustiva explicación de la concepción relativista de la democracia liberal o procedimental defendida por Kelsen ${ }^{9}$ —entre otros destacados pensadores-, en virtud de la cual todas las creencias y opiniones políticas deben ser respetadas, de manera que estas puedan difundirse y adquirir una adhesión mayoritaria por los ciudadanos ${ }^{10}$.

Para sus detractores — son de destacar a Schmitt ${ }^{11}$ y a Laun—, en cambio, el relativismo democrático posibilita la destrucción del propio régimen político. Y es que, tal y como afirman dichos autores, aceptar que no existen ciertos principios o valores éticos absolutos implica la legitimidad de la defensa de ideas contrarias a cualquier sentimiento de justicia, las cuales pueden llegar además a convertirse en

7 Concepto para el cual, tal y como advierte LASKY, H. J., «Democracia», en Seligman E. R. A. (Ed.) Encyclopedia of the Social Sciences, vol. V, The Macmillan Company, 1959, New York, p. 76, no existe ninguna definición que comprenda su vasto despliegue histórico.

${ }^{8}$ MERINO MERCHÁN, J. F., PÉREZ-UGENA COROMINA, M., y VERA SANTOS, J. M., Lecciones de Derecho Constitucional, Tecnos, 1997, pp. 52 y 53.

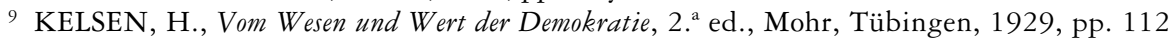
y ss.

10 LUCAS VERDÚ, P., Curso de Derecho Político, vol. II, Tecnos, Madrid, 1983, pp. 243 y ss.

11 Aunque su deriva ideológica le llevará a abogar por la implantación del «Estado total», es decir, un régimen en el que la intervención estatal es máxima, negando el pluralismo político. Sobre la construcción teórica completa del autor alemán al respecto, SCHMITT, C., Die geistesgeschichtliche Lage des beutigen Parlamentarismus, Duncker \& Humblot, München, 1923. 
mayoritarias, como ya sucedería con el fascismo, el nacionalsocialismo o el comunismo. Pues bien, es precisamente esta forma de pensar la que ha acabado por imponerse entre la doctrina mayoritaria contemporánea pues, pese a ciertas diferencias conceptuales, se encuentra ampliamente aceptada la idea de una democracia que tiene, no solo el derecho a defenderse frente a quienes no creen en ella ${ }^{12}$, sino el deber de «creer en lo que propugna y defenderlo con fuerza, con toda la fuerza y por todos los medios que le permita el ser un Estado democrático de Derecho» ${ }^{13}$. No extraña, por ende, que la prohibición de partidos extremistas constituya una práctica a la que se ha recurrido con «sorprendente regularidad en las sociedades democráticas» ${ }^{14}$.

\subsection{Cláusulas expresas de intangibilidad y control ideológico}

Centrado este trabajo, como está, en el control ejercido sobre los partidos políticos en cuanto que auténticos protagonistas de la vida política ${ }^{15}$, las mayores discrepancias doctrinales se producen en relación con la siguiente cuestión: se discute si, más allá de lo previsto por las leyes penales, cabe la fiscalización de los fines perseguidos por dichas asociaciones en los Estados cuyas constituciones no hayan optado por la inclusión de límites expresos para su reforma. En otras palabras, si toda propuesta política debe tener cabida en democracia, siempre que su materialización se persiga respetando las reglas establecidas y a menos que la Constitución prohíba expresamente la alteración de los mismos elementos jurídicos que aquel proyecto pretende cambiar, tal y como veremos que hace Alemania, arquetipo del concepto de democracia militante ${ }^{16}$.

En tal sentido, y habiendo tenido ya ocasión de reflejar las principales posturas doctrinales en un estudio anterior ${ }^{17}$, baste aquí reiterar nuestra posición favorable

12 LUCAS VERDÚ, Curso de Derecho Político, op. cit., pp. 243 y ss.

13 TORRES DEL MORAL, A., «Terrorismo y principio democrático», en Revista de derecho político, N. ${ }^{\circ} 78$, mayo-diciembre 2010, p. 147. Para una recapitulación de los trabajos favorables a esta idea, consúltese CAPOCCIA, G., «Militant Democracy: The Institutional Bases of Democratic SelfPreservation», en Annual Review of Law and Social Science, Vol. 9, 2013, pp. 207-226.

14 ISSACHARROFF, S., «Fragile democracias», en Harvard Law Review, Vol. 120, Number 6, April 2007, p. 1409.

${ }^{15}$ Lo que ha llevado a la doctrina a hablar de un auténtico «Estado de partidos», tal y como recuerda el Tribunal Constitucional español en su Sentencia 3/1981, de 2 de febrero, FJ 1. En el mismo sentido, DE VEGA, P., Legitimidad y representación en la crisis de la Democracia actual, Universidad Complutense de Madrid, 1998, p. 26.

${ }^{16}$ Resulta muy interesante, al respecto, la distinción que DENNINGER, E., «Democracia militante y defensa de la Constitución», en Benda, E., Maihofer, W., y Vogel, H. J. (dirs.) Manual de Derecho Constitucional,

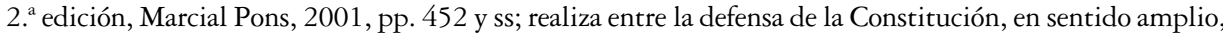
y la defensa del «orden fundamental libre y democrático», desde un punto de vista específico.

17 Véase FERNÁNDEZ DE CASADEVANTE MAYORDOMO, P. «La prohibición de formaciones políticas como mecanismo de defensa del Estado y el debilitamiento de dicha protección 
— aunque de seguimiento minoritario en nuestro país - a la constitucionalidad del control ideológico de los partidos, ello independientemente de la existencia de las mencionadas cláusulas de intangibilidad ${ }^{18}$. Y es que, partiendo de la idea de que todo texto constitucional supone la consagración de una serie de valores jurídicos indeterminados que dan forma al modelo democrático que, por tanto, «no es un régimen éticamente neutral o agnóstico» ${ }^{19}$, pensamos que no es que esta ideología merezca una protección superior a cualquier otra, sino que debe ser la única válida de cara a ordenar la convivencia en sociedad. Es por ello que estamos de acuerdo con quien afirma que «la democracia es militante o no es democracia, con independencia de cuál sea el procedimiento de reforma constitucional y la ausencia o no de límites materiales expresos a dicha reforma» ${ }^{20}$. Dicho de otro modo, «no puede haber democracia no militante, democracia a la que no le importe dejar de serlo. Eso sería una democracia contradictoria, una democracia bajo sospecha, una pseudodemocracia» ${ }^{21}$.

tras las polémicas decisiones sobre Bildu y Sortu», en Revista Europea de Derechos Fundamentales, núm. 26, Editorial Comares, Madrid, 2015, pp. 113 a 123.

${ }^{18}$ Citando a nuestros clásicos, al frente de la corriente doctrinal mayoritaria se encuentran ARAGÓN REYES, M., Constitución, Estado Constitucional, Partidos y Elecciones, y Fuentes del Derecho, VVAA, Tomo I, Aranzadi, Navarra, 2011, pp. 80 y 81; DE OTTO PARDO, I., Defensa de la Constitución y Partidos Políticos, Centro de Estudios Constitucionales, Madrid, 1985, pp. 35 y 36; JIMÉNEZ CAMPO, J., «Sobre el régimen jurídico-constitucional de los partidos políticos», en Revista de Derecho Político, núm. 26, UNED, Madrid, 1988, p. 24; y SOLOZÁBAL ECHAVARRIA, J. J., «Sobre la constitucionalización de los partidos políticos en el derecho constitucional y en el ordenamiento español», en Revista de Estudios Políticos, núm. 45, mayo-junio, 1985, p. 163.

19 TORRES DEL MORAL, «Terrorismo y principio democrático», op. cit., p. 145, para quien la democracia «profesa unos valores, una ética que se vierte en el Ordenamiento jurídico. Por consiguiente, tampoco son éticamente agnósticas la democracia española ni la Constitución que le da forma jurídica (...)». En la misma línea, el propio autor, en «La inconstitucionalidad de los partidos. A propósito de la Ley 6/2002 de Partidos Políticos», en Revista de Derecho Político, núm. 60, UNED, Madrid, 2004, p. 63, alude a los valores superiores del ordenamiento jurídico del artículo 1.1 CE como precepto que impide que la reforma constitucional sirva para la aprobación de un texto antidemocrático.

20 ÁlVAREZ CONDE, E. y CATALÀ I BAS, A., El derecho de partidos, 2. ${ }^{a}$ edición, Colex, Madrid, 2013, p. 148. En contra de dicha postura se pronuncia FORSTHOFF, E., «Die Umbildung des Verfassungsgesetzes, en Festschrift für Carl Schmitt, Duncker \& Humblot, Berlin, 1959, pp. 117 y ss., uno de los principales referentes en Alemania a la hora de defender el concepto kelseniano de «Constitución material». Para él, la consideración del texto fundamental como un «sistema de valor» abriría de forma peligrosa la puerta al aumento de la discrecionalidad judicial y, por ende, hacia la inseguridad jurídica, y ello al rechazar los principios clásicos de interpretación de la ley. Entre la propia doctrina alemana, dicha tesis es rebatida, entre otros, por BACHOF, O., Jueces y Constitución, Cuadernos Taurus, Madrid, 1963, p. 28; y HOLLERBACH, A., «Auflösung der rechtsstaatlichen Verfassung?», en Archiv des öffentlichen Rechts, núm. 85 (octubre 1960), pp. 241-270. Más al respecto en, JIMÉNEZ CAMPO, J., «Algunos problemas de interpretación en torno al título X de la Constitución», en Revista del Departamento de Derecho Político, núm. 7, UNED, Madrid, 1980, pp. 89 y ss.

${ }_{21}^{21}$ TORRES DEL MORAL, A., «Democracia militante», en VVAA Derecho Constitucional para el siglo XXI, Tomo I, Thomson-Aranzadi, Navarra, 2006, pp. 219 y 220. 
Pero es que, además, estamos convencidos de que dicha forma de entender la democracia militante es plenamente conforme con el CEDH, y ello en atención a lo dispuesto en sus artículos 10,11 y 17. Comenzando por este último ${ }^{22}$, y aunque en un principio cabría pensar que contempla únicamente la represión de actividades ilegales de un partido, y no su ideología, parece lógico realizar una interpretación más extensa. Es decir, que sería posible la aplicación del precepto ante la mera pretensión, por parte de una formación antidemocrática, de alcanzar el poder por las vías legales establecidas. Y ello, al tratarse precisamente de eso, de una serie de actos — por ejemplo, los propios de una campaña electoral para la captación de votos- dirigidos a la destrucción del régimen de derechos y libertades que la Convención configura ${ }^{23}$.

Y respecto a los artículos 10 y $11 \mathrm{CEDH}$, no solo suponen la consagración de los derechos a la libertad de expresión, de un lado, y a la libertad de reunión y de asociación, de otro. En efecto, y centrándonos en el artículo $11.2 \mathrm{CEDH}^{24}$, observamos que plasma por escrito algunos de esos valores jurídicos indeterminados propios de toda democracia, los cuales sirven, a su vez, como límites a los derechos reconocidos. En concreto, no cabrán «otras restricciones que aquellas que, previstas por la ley, constituyan medidas necesarias, en una sociedad democrática, para la seguridad nacional, la seguridad pública, la defensa del orden y la prevención del delito, la protección de la salud o de la moral, o la protección de los derechos y libertades ajenos».

22 Artículo $17 \mathrm{CEDH}$ : «Ninguna de las disposiciones del presente Convenio podrá ser interpretada en el sentido de que implique para un Estado, grupo o individuo, un derecho cualquiera a dedicarse a una actividad o a realizar un acto tendente a la destrucción de los derechos o libertades reconocidos en el presente Convenio o a limitaciones más amplias de estos derechos o libertades que las previstas en el mismo». En opinión de GARCÍA ROCA, J., "Abuso de los derechos fundamentales y defensa de la democracia», en García Roca, J., y Santolaya, P. (coords.) La Europa de los derechos. El Convenio Europeo de Derechos Humanos, Centro de Estudios Políticos y Constitucionales, Madrid, 2005, p. 808 , este precepto responde a la idea de «la defensa de la democracia frente a la democracia hasta el suicidio».

${ }^{23}$ Sea como fuere, no es habitual que el TEDH recurra a dicho precepto a la hora de pronunciarse sobre la prohibición de partidos políticos — sí lo hizo, en cambio, la Comisión de Derechos Humanos cuando hubo de resolver sobre la disolución del KPD alemán, en 1957-, fijándose particularmente en los requisitos previstos en el artículo 11.2 CEDH. Crítico con esta infrautilización del artículo $17 \mathrm{CEDH}$ se muestra CORCUERA, J., TAJADURA, J. y VÍRGALA FORURIA, E., La ilegalización de partidos políticos en las democracias occidentales, Dykinson, Madrid, 2008, p. 303.

${ }^{24}$ En las demandas de este tipo ante el TEDH, tan frecuente es que se alegue la vulneración conjunta de los artículos 10 y $11 \mathrm{CEDH}$, como que el Tribunal, tras examinar los hechos a la luz de ese último precepto, considere innecesario analizar los mismos hechos separadamente, esta vez bajo el prisma del artículo $10 \mathrm{CEDH}$. Así se desprende, por ejemplo, de las SSTEDH de 13 de febrero de 2003, Asunto Partido de la Prosperidad y otros c. Turquía, Gran Sala; de 30 de junio de 2009, Asunto Herri Batasuna y Batasuna c. España, párrafos 96 y 97; de 30 de junio de 2009, Asunto Herritarren Zerrenda c. España, párrafos 44 a 49; y de 15 de enero de 2013, Asunto Abertzale Ekintza-Acción Nacionalista Vasca c. España. 
Identificados pues los límites concretos ${ }^{25}$, y partiendo de la premisa de que todos los proyectos son válidos en una democracia aunque no se compartan, incluso aunque nos molesten o inquieten ${ }^{26}$, podemos identificar ya los tres requisitos que deben concurrir a la hora de considerar justificada la injerencia en un derecho, en este caso, la prohibición de una formación política. Y aunque los desarrollaremos más tarde, basta aquí saber que la restricción: 1. Ha de estar prevista por la ley. 2. Debe además estar justificada para alcanzar fines legítimos, concretos y predeterminados — los expresamente señalados en el párrafo anterior- 3. Ha de ser una medida necesaria en una sociedad democrática.

Finalmente, y como corolario de todo lo señalado hasta ahora, téngase en cuenta que el TEDH exige otras dos condiciones a aquéllos partidos políticos que pretendan un cambio en la legislación o en las estructuras legales y constitucionales de un Estado: por un lado, los medios empleados para ello deben ser indudablemente legales y democráticos y; por otro, el cambio pretendido ha de ser compatible con los principios democráticos ${ }^{27}$, es decir, y estas son ya palabras nuestras, la ideología que pretenda implantar el partido en cuestión no puede ser otra que la democracia, lo cual confirma la constitucionalidad del control ideológico de los partidos, independientemente de la existencia o no de límites expresos a la reforma constitucional en el texto fundamental de cualquier Estado. Y es que, como se desprende de este último párrafo, el TEDH «se pronuncia, sin ningún género de dudas por una concepción sustantiva y no meramente procedimental de la democracia» ${ }^{28}$, plenamente coherente con su concepción del sistema democrático como único modelo compatible con el Convenio ${ }^{29}$.

${ }^{25}$ Cuyo significado y alcance se encuentra explicado en BUSTOS GISBERT, «Los derechos de libre comunicación en una sociedad democrática», en García Roca, y Santolaya (coords.) La Europa de los Derechos. El Convenio Europeo de Derechos Humanos, op. cit., p. 613 y ss; y CATALÀ I BAS, Libertad de expresión e información. La jurisprudencia del TEDH..., op. cit., p. 305 y ss. Ver igualmente, por ejemplo, las SSTEDH Asunto Janowski contra Polonia, de 21 de enero de 1999, párrafos 25 y 26; y Asunto Rekvényi contra Hungría, de 20 de mayo de 1999, párrafos 39, 40 y 41.

${ }^{26}$ Entre otras, las SSTEDH de 7 de diciembre de 1976, Asunto Handyside c. Reino Unido, párrafo 49; de 23 de septiembre de 1994, Asunto Jersild c. Dinamarca, Gran Sala, párrafo 37; de 30 de enero de 1998, Asunto Partido Comunista Unificado de Turquía c. Turquía, párrafo 43; de 13 de febrero de 2003, Asunto Partido de la Prosperidad y otros c. Turquía, Gran Sala, párrafo 89; de 30 de junio de 2009, Asunto Herri Batasuna y Batasuna c. España, párrafo 76; y de 14 de diciembre de 2010, Asunto Hadep y Demir c. Turquía, párrafo 57.

${ }_{27}$ Por ejemplo, las SSTEDH de 9 de abril de 2002, Asunto Yazar y otros c. Turquía, párrafo 49; de 13 de febrero de 2003, Gran Sala, Asunto Partido de la Prosperidad y otros c. Turquía, párrafo 98; y de 30 de junio de 2009, Asunto Herri Batasuna y Batasuna c. España, párrafo 79.

${ }^{28}$ CORCUERA, TAJADURA y VÍRGALA FORURIA, La ilegalización de partidos políticos..., op. cit., p. 303.

29 STEDH de 30 de enero de 1998, Asunto Partido Unificado de Turquía y otros c. Turquía, párrafo 45. 


\section{DEFENSA DE LA DEMOCRACIA Y PARTIDOS POLÍTICOS EN EL ORDENAMIENTO JURÍDICO ALEMÁN}

\subsection{El concepto alemán de democracia militante}

El debate relativo al establecimiento de límites a la actividad y/o ideología de los partidos políticos adquirió gran intensidad en Alemania poco tiempo antes de la caída de la República de Weimar, y por lo tanto, también justo antes del inicio de la II Guerra Mundial.

Para ser más exactos, fue Karl Loewenstein quien, desde su exilio en Estados Unidos, reflexionó acerca de la necesidad de salvar la democracia alemana, muy próxima a claudicar ante el empuje del autoritarismo nazi. En este sentido, defendió la conveniencia de establecer una democracia militante, democracia combativa, streitbare Demokratie o werhafte Demokratie, entendida como la implantación de una serie de reglas dentro del sistema, de manera que no todas las ideas fueran legítimas, sin importar el número de adeptos que estas pudieran tener ${ }^{30}$. Y es que, como es conocido, Adolf Hitler se valió de instrumentos propios del Estado de Derecho ${ }^{31}$ para alcanzar el poder más absoluto, acabar con el sistema democrático alemán y dar comienzo al III Reich, con sus consabidas consecuencias.

No sería hasta 1949 cuando los planteamientos defendidos por Loewenstein encontrasen su plasmación normativa, teniendo ello lugar a través de la Ley Fundamental de Bonn — LFB_, mediante el establecimiento de «una serie de instrumentos tendentes a la prevención y represión de acciones políticas subversivas respecto de los valores puestos como fundamento del ordenamiento constitucional» ${ }^{32}$. En concreto, y con carácter preventivo, dicho Texto contempla, entre otros aspectos ${ }^{33}$ :

- la prohibición de las asociaciones cuyos fines o actividades sean contrarios a las leyes penales o estén dirigidas contra el orden constitucional o contra la idea del entendimiento entre los pueblos — artículo 9.2 LFB—.

30 LOEWENSTEIN, K., «Militant Democracy and Fundamental Rights II», en The American Political Sciences Review, vol. 31, núm. 4, Agosto 1937, pp. 638-658. Ello en respuesta a la pregunta planteada por POPPER, K., La sociedad abierta y sus enemigos, Barcelona, Paidós, 1991, pp. 511 y 512 ; en el sentido de si se debe «permitir a los enemigos de la democracia utilizar la maquinaria democrática con el único propósito de derrocar la democracia».

31 Es lo que STERN, K., Derecho del Estado de la República Federal Alemana, Madrid, Centro de Estudios Constitucionales, 1987, p. 386, vino a denominar «revolución legal» del dictador.

32 TENORIO SÁNCHEZ, P., Constitución, derechos fundamentales y seguridad. Panorama comparativo, Civitas, Madrid, 2010, p. 125.

33 Como señala DENNINGER, «Democracia militante y defensa de la Constitución», op. cit., pp. 460 y 461, «la Ley Fundamental no emplea ninguna caracterización equivalente, unitaria, para los bienes constitucionales a proteger. Más bien se confía a la doctrina y a la jurisprudencia la tarea de desarrollar una conceptualización lo más clara posible». 
— la posibilidad de privar de derechos fundamentales a quien los emplee abusivamente para combatir el régimen fundamental de libertad y democracia - artículo $18 \mathrm{LFB}^{34}$-.

— la declaración de la inconstitucionalidad o exclusión de la financiación estatal de aquellos partidos que, por sus fines o por el comportamiento de sus simpatizantes, tiendan a desvirtuar o eliminar el orden fundamental libre y democrático, o a poner en peligro la existencia de la República Federal de Alemania - artículo 21 LFB-.

- La prohibición, prevista en el artículo 79.3 LFB y que recoge la denominada Ewigkeitsklausel o cláusula de intangibilidad ${ }^{35}$, de proceder a cualquier reforma constitucional que afecte a la organización de la Federación en Länder, al principio de la participación de los mismos en la legislación, o a los principios enumerados en los artículos $1^{36}$ y $20 \mathrm{LFB}^{37}$.

A tenor de lo visto, podemos afirmar que la LFB ha optado por un sistema de defensa basado en el establecimiento de «un espacio de seguridad constitucional, a cambio del recorte de la libertad política» ${ }^{38}$ que, a pesar de sus implicaciones constitucionales, ya ha llevado a la prohibición de dos partidos políticos: la primera, en 1952, con ocasión de la exclusión del Partido Socialista del Reich

34 Estos derechos son la libertad de expresión y opinión, particularmente la libertad de prensa —artículo 5.1—, la libertad de enseñanza —artículo 5.3-, de reunión —artículo 8-, de asociación —artículo 9-, del secreto de las comunicaciones postales y de las telecomunicaciones —artículo 10—, así como del derecho de propiedad —artículo 14—y del de asilo —artículo 16 a)—.

35 Tal y como aclara ARNOLD, R., «La reforma constitucional en Alemania», en Revista de Derecho Político», núm. 37, 1992, p. 376, el hecho de que las restricciones materiales establecidas por dicha cláusula afecten únicamente al poder constituido no implica la consideración del poder constituyente como un "poder revolucionario absolutamente ilimitado». En concreto, afirma, también este debe estar sujeto, en su acción, «a la observancia de ciertos principios fundamentales como son el de la dignidad humana o el del Estado Social y de Derecho, en tanto que valores de naturaleza cultural-normativa resultantes de la evolución histórica».

36 Estos son el carácter intangible de la dignidad humana, que deberá ser respetada y protegida por los poderes públicos; el respeto a los derechos humanos inviolables e inalienables; y la consideración de estos como derecho directamente aplicable.

37 En él se consagra la condición de la República Federal de Alemania como Estado federal democrático y social; el principio de soberanía popular; el sometimiento de los poderes públicos a la Constitución y al resto del ordenamiento jurídico; así como el reconocimiento a todos los alemanes del derecho de resistencia, cuando no fuere posible otro recurso, contra cualquiera que intente eliminar el orden democrático establecido. Más sobre el concepto de democracia militante aplicable a la prohibición de partidos en MEYER, H., «Parteiverbote und «Streitbare Demokratie»-Einige Thesen», en Lichdi, J., (dir.) Darf die NPD gegen Taten parteioser Neonazis verboten werden?, Weiterdenken-Heinrich-BöllStiftung Sachsen und der Amadeu-Antonio-Stiftung, 2016, pp. 11-15; y SICHERT, M., «Das Parteiverbot in der wehrhaften Demokratie. Keine Toleranz gegenüber den Feinden der Toleranz!?», en Die Öffentliche Verwaltung 2001, S.671 - 681.

38 HINAJEROS PARGA, A., «La prohibición de partidos como mecanismo de defensa del Estado», en Teoría y Realidad Constitucional, núms. 10-11, 2. ${ }^{\circ}$ semestre 2002-1er semestre 2003, UNED, Madrid, p. 474. 
—o Sozialistische Reichspartei, desde ahora SRP_-; y la segunda, para hacer lo propio con el Partido Comunista de Alemania —o Kommunistische Partei, KPD en adelante-, en $1956^{39}$.

Y fue precisamente a raíz de este último caso cuando el concepto de democracia militante fue asumido también en el ámbito jurisdiccional. En concreto, el Tribunal Constitucional Federal declaró, al resolver el asunto en cuestión, que «la Ley Fundamental representa un esfuerzo consciente para lograr una síntesis entre el principio de tolerancia para todas las ideas políticas y ciertos valores inalienables del sistema político. El artículo 21.2 no contradice ningún principio básico de la Constitución; expresa la convicción de los [padres fundadores], basados en su concreta experiencia histórica, de que el Estado no puede seguir manteniendo una actitud de neutralidad hacia los partidos políticos. [La Ley Fundamental] ha creado en este sentido una «democracia militante», una decisión de valor constitucional que vincula al Tribunal Constitucional Federal» ${ }^{40}$.

\subsection{Régimen jurídico aplicable a los partidos políticos antidemocráticos}

Descritos los principales mecanismos que la Ley Fundamental de Bonn configura de cara a tratar de impedir la quiebra del sistema de protección de derechos y libertades establecido en 1949, a partir de ahora nos centraremos exclusivamente en las medidas concretas que dicha Norma establece en relación con los partidos políticos contrarios a los valores democráticos. Y es que, lejos de tratarse de una cuestión exenta de relevancia actual, la reciente resolución del Tribunal Constitucional Federal en relación con la no prohibición del Partido Nacionaldemócrata de Alemania — desde ahora, $\mathrm{NPD}^{41}$ — ha dado lugar a importantes modificaciones, tanto en la Constitución alemana como en su legislación de desarrollo, amén de las consideraciones que son necesarias realizar en relación con la adaptación de dicha decisión a la profusa jurisprudencia del TEDH existente en materia de prohibición de partidos políticos.

39 En ambos casos, la petición de declaración de inconstitucionalidad fue presentada por el Gobierno federal en noviembre de 1951. Y aunque el partido que más preocupaba al Ejecutivo era el KPD, STOLLEIS, M., «Prohibición de partidos y exclusión política en la República de Bonn», en la ponencia presentada con motivo del Seminario Internacional titulado Mecanismos de exclusión en la democracia de partidos, celebrado en la UNED, Madrid, el día 5 de abril de 2017, disponible online en https://canal.uned.es/mmobj/index/id/56114, afirma que «motivos de simetría política» llevaron al Ejecutivo a solicitar igualmente la prohibición de la SRP, pequeño partido radical de derechas, compuesto por antiguos nacionalsocialistas. Más, del mismo autor, en «La justicia política en Alemania occidental», en Gutiérrez Gutiérrez, Ignacio (coord.) Mecanismos de exclusión en la democracia de partidos, Marcial Pons, Madrid, 2017.

${ }^{40}$ BVerfGE 5, 85 (139). Sobre este tema, KOMMERS, D. P., The Constitutional Jurisprudence of the Federal Republic of Germany, 2. ' edición, Durham (Carolina del Norte), Duke University Press, 1997, p. 223.

41 Por su nombre en alemán, Nationaldemokratische Partei Deutschlands. 


\subsubsection{Marco constitucional}

\section{a. La declaración de inconstitucionalidad del artículo 21.2 LFB}

Como ya se ha indicado antes, la Constitución alemana contempla la prohibición de asociaciones en dos supuestos: el primero, en el artículo $9.2 \mathrm{LFB}^{42}$, y el segundo, en el artículo $21.2 \mathrm{LFB}^{43}$, que es el que aquí nos interesa ${ }^{44}$. Y es que, partiendo de la consagración constitucional de la libre fundación de los partidos políticos en cuanto que sujetos que participan en la formación de la voluntad política del pueblo ${ }^{45}$, ese último precepto —ejemplo único, dentro de la Europa continental, de prohibición de partidos políticos a nivel constitucional ${ }^{46}$ - contiene una importante implicación de tipo garantista: a diferencia del resto de asociaciones a las que se refiere el artículo 9.2 LFB, que podrán ser prohibidas por el Gobierno ${ }^{47}$, la potestad para pronunciarse sobre la inconstitucionalidad de un partido político - e «indirectamente, la competencia de definir qué se debe entender por ordenamiento democrático ${ }^{48}$ - , recae exclusivamente en el Tribunal Constitucional Federal $^{49}$, ello según el artículo 21.4 LFB.

42 Tras consagrar el artículo 9.1 LFB el derecho fundamental de creación de asociaciones.

43 Artículo 21.2 LFB: «Los partidos que por sus fines o por el comportamiento de sus adherentes tiendan a desvirtuar o eliminar el orden fundamental libre y democrático, o a poner en peligro la existencia de la República Federal de Alemania, son inconstitucionales. Sobre la constitucionalidad decidirá el Tribunal Constitucional Federal».

${ }^{4}$ Pues, como ha apuntado el Tribunal Constitucional Federal, pese a que ambos preceptos son aplicables, el artículo 21 LFB actúa como «lex specialis»-BVerGE 2, 1 (13); y BVerfGE, Urt. v. 17.1.2017 - $2 \mathrm{BvB} 1 / 13$, Rn. 595. Por lo tanto, y como recuerda ZIEKOFF, J., «Vereinigungsfreiheit», en Handbuch der Grundrechte in Deutschland und Europa, Band IV, Müller, Heidelberg, 2011, p. 1244, aunque el artículo 21 LFB privilegia a los partidos políticos frente a otras asociaciones, eso no significa que las previsiones del artículo 9.2 LFB se encuentren en un plano de subsidiariedad con respecto a las del primer precepto. Y ello, porque el artículo 21 LFB tiene prioridad únicamente en la medida en que contenga normas más específicas que la libertad general de asociación.

45 Artículo 21.1 LFB.

${ }^{46}$ Lo cual no obsta para que otros muchos ordenamientos jurídicos, incluido el español, prevean la prohibición aunque sea a nivel legislativo.

${ }^{47}$ En concreto, el Ministro del Interior, si la organización o actividad de la asociación o parte de ella se extiende más allá del territorio de un Land. En caso contrario, la decisión la podrá adoptar el Gobierno regional —artículo 3 de la Ley de Asociaciones o Vereinsgesetz - VereinsG_.

48 TENORIO SÁNCHEZ, Constitución, derechos fundamentales y seguridad..., op. cit., p. 125.

49 Atribución que es aplaudida por RENSMANN, T., «Procedural Fairness in a Militant Democracy: The «Uprising of the Decent» Fails Before the Federal Constitutional Court», en German Law Journal, vol. 4, núm. 11, 2003, p. 1119, edición digital, consultada el 7 de diciembre de 2017, https://static1. squarespace.com/static/56330ad3e4b0733dcc0c8495/t/56b96e2122482e110fab1f34/1454992929978/ GLJ_Vol_04_No_11_Rensmann.pdf, al entender que impide a los órganos políticos manejar los instrumentos de la democracia militante. 
Aclarado lo anterior, procede ahora estudiar con más detenimiento las dos situaciones que pueden dar lugar a dicha inconstitucionalidad. Recordemos, primero, la tendencia a desvirtuar o eliminar el orden fundamental libre y democrático; y segundo, la puesta en peligro de la existencia de la República Federal de Alemania.

Comenzando por el significado de la expresión «orden fundamental libre y democrático», el Tribunal Constitucional Federal volvió a descartar, en su Sentencia de 17 de enero de 2017, la identificación de dicho concepto jurídico indeterminado con la totalidad de los principios declarados intangibles por el artículo $79.3 \mathrm{LFB}^{50}$. Lo había hecho ya con motivo de los procesos de prohibición del SRP y del KPD, al ligar aquella terminología, en el primer caso, al respeto de los derechos humanos concretados en la Constitución alemana, sobre todo al derecho a la vida y al libre desarrollo, la soberanía popular, la división de poderes, la responsabilidad del Gobierno, el principio de legalidad de la Administración, la independencia de los tribunales, el principio pluripartidista y la igualdad de oportunidades para los diferentes partidos, incluido el derecho a la formación y ejercicio de la oposición» ${ }^{51}$. Y en el segundo, al realzar la dignidad del hombre como valor supremo en un orden libre y democrático, la libertad del espíritu, el debate de las ideas y la igualdad de trato entre todos como elementos inherentes al orden libre y democrático ${ }^{52}$. En otros casos posteriores, ha subrayado la importancia de la libertad de expresión ${ }^{53}$, la libertad de radiodifusión, prensa e información ${ }^{54}$, la neutralidad reli$\operatorname{gios}^{55}$, la libre formación de la opinión y voluntad popular ${ }^{56}$, así como la igual valoración de todos los ciudadanos en el ejercicio del derecho de sufragio ${ }^{57}$. E inexorablemente conectado con todo lo anterior se encuentra asimismo el artículo 1.1 LFB, relativo a la dignidad humana, tal y como ha señalado el Alto Tribunal en repetidas ocasiones ${ }^{58}$.

${ }^{50}$ BVerfGE, Urt. v. 17.1.2017 - 2 BvB 1/13, Rn. 229 y 536 y ss. Entre dichos principios se encuentran recogidos, como nos recuerda DENNINGER, «Democracia militante y defensa de la Constitución», op. cit., p. 463, la federalidad, el postulado del Estado social y la forma republicana de Estado. El propio autor, tras adherirse a esa forma de pensar propia del Tribunal Constitucional Federal, hace referencia a la doctrina principal contraria a estos postulados.

51 BVerGE 2, 1 (13).

52 BVerfGE 5, 85 (205).

53 BVerfGE 7, 198 (208)

54 BVerfGE 77, 65 (74).

55 BVerfGE 27, 195 (201).

56 BVerfGE 44, 125 (139).

57 Para MEIER, H., Parteiverbote und demokratische Republik: Zur Interpretation und Kritik von art 21 abs 2 des Grund Gesetzes, Baden-Baden, 1993, pp. 288 y ss., al entender que lo que se protege son los principios esenciales de la democracia, es decir, los derechos fundamentales, el parlamentarismo y la separación de poderes. Más sobre esta cuestión en KLEIN, E., Ein neues NPD-Verbotsverfabren? Rechtsprobleme beim Verbot politischer Parteien, Nomos, Baden-Baden, 2012, pp. 16 a 19. Ver también NICHELMANN, R., Form und Funktion der «freibeitlichen demokratischen Grundordnung», Duncker \& Humblot, Berlin, 2013.

58 BVerfGE 12, 45 (53); 27, 1 (6); 35, 202 (225); 45, 187 (229); 49, 286 (298); 87, 209 (228) y BVerfGE, Urt. v. 17.1.2017 - 2 BvB 1/13, Rn. 533. Para un estudio muy pormenorizado sobre dicho concepto, ISENSEE, J., Würde des Menschen, en Handbuch der Grundrechte in Deutschland und Europa, Band IV, Müller, Heidelberg, 2011, pp. 3-136. 
Pues bien, en relación con todo ello, el Tribunal Constitucional Federal ha señalado que, para hablar de eliminación del orden fundamental libre y democrático bastará con la erradicación de uno de los numerosos elementos básicos que se acaban de enumerar ${ }^{59}$. En cambio, para hablar de «desvirtuación», se exigirá que la formación en cuestión represente, con razonable intensidad y en base a su estrategia política, una amenaza significativa sobre aquel orden ${ }^{60}$.

Refirámonos ahora a la segunda causa de inconstitucionalidad del artículo 21.2 LFB, relativa a la puesta en peligro de «la existencia de la República Federal alemana». Tiene mucho sentido asociar dicha expresión a la idea de la existencia y unidad estatal de la República Federal como tal, a su capacidad de funcionamiento, tanto en el ámbito internacional — como sujeto de Derecho Internacional- como a nivel interno - en cuanto que poder social de ordenación-, a su integridad territorial y a la existencia física de los habitantes del territorio federal ${ }^{61}$. Y también parece razonable negar que cualquier perturbación de la seguridad y el orden públicos, que condicione la operatividad de determinadas instituciones del Estado, pueda justificar el recurso a los instrumentos de defensa constitucionalmente previstos ${ }^{62}$. «La amenaza debe afectar más bien a la existencia del Estado en su sustantividad territorial humana o soberana» ${ }^{63}$.

b. La posibilidad de exclusión de la financiación estatal como alternativa a la prohibición —artículo 21.3 LFB-

No podemos finalizar este apartado sin hacer alusión a la reciente reforma obrada en el artículo $21 \mathrm{LFB}^{64}$, a partir de la cual podrá impedirse que partidos políticos antidemocráticos, aun sin haber sido declarados inconstitucionales, sigan disfrutando de recursos económicos procedentes del erario público, así como de otras ventajas

59 BVerfGE, Urt. v. 17.1.2017 - 2 BvB 1/13, Rn. 550. En esa línea, consúltese GELBERG, T. A., Das Parteiverbotsverfabren nach Art. 21 Abs. 2 GG am Beispiel des NPD-Verbotsverfabrens, V \& R Unipress, Göttingen, 2009, p. 202.

${ }^{60}$ BVerfGE, Urt. v. 17.1.2017 - 2 BvB 1/13, Rn. 556.

61 DENNINGER, «Democracia militante y defensa de la Constitución», op. cit., pp. 465 y 466.

62 Tales como los de los artículos 21.2, 87 a) o 91 LFB.

${ }^{63}$ DENNINGER, «Democracia militante y defensa de la Constitución», op. cit., p. 466, citando a modo de ejemplos, entre otros, la explosión de bombas a cargo de terroristas movidos por motivaciones políticas, acciones violentas con intenciones separatistas. En cambio, no entrarían en este supuesto los episodios de crisis económica, desempleo masivo, huelgas laborales, manifestaciones pacíficas de considerables dimensiones o movimientos civiles pacíficos exigiendo una reordenación del territorio federal, o la existencia de partidos políticos que pretendan un cambio en la forma y estructura del Estado —en este último caso, por la necesidad de poner esa «existencia de la República Federal de Alemania» en relación con la referencia al «orden fundamental libre y democrático»—. De esta forma, un partido que pretendiera la sustitución de la República Federal por una Monarquía parlamentaria, o una mayor centralización del poder al estilo de lo que hace Francia, serían perfectamente constitucionales, tal y como se desprende de la BVerfGE, Urt. v. 17.1.2017 - 2 BvB 1/13, Rn. 537.

64 En vigor desde el 7 de julio de 2017. 
fiscales. Dicha modificación se produjo tras la aludida Sentencia dictada por el Tribunal Constitucional Federal en relación con el partido ultraderechista del NPD, y sobre cuyo contenido ya tendremos ocasión de detenernos más adelante. Sirva como adelanto, en cualquier caso, el hecho de que el Alto Tribunal sugiriese al Estado que, al margen de la declaración de inconstitucionalidad prevista en el artículo 21.2 LFB, existen otras posibles sanciones a implementar, poniendo como ejemplo de ello la reducción o cancelación de recursos financieros públicos ${ }^{65}$, aunque recordando al mismo tiempo la imposibilidad de adoptar dicha medida a tenor de la redacción de la Constitución alemana vigente al momento de dictarse la mencionada Sentencia ${ }^{66}$.

La consecuencia de todo ello, la reforma constitucional ya descrita, de manera que, desde julio del año 2017 —y amén de lo ya apuntado en relación con la prohibición de partidos contemplada en el artículo 21.2 LFB — , aquellas formaciones que, en atención a sus fines o al comportamiento de sus adherentes, tengan como objetivo desvirtuar o eliminar el orden básico democrático libre o poner en peligro la existencia de la República Federal de Alemania ${ }^{67}$, quedarán excluidas de la financiación estatal, eliminándose asimismo toda ventaja fiscal, tanto en relación con dichos partidos como con las donaciones a ellos realizadas — artículo 21.3 LFB_-

Y finalmente, apuntar que, de nuevo aquí, la competencia exclusiva para resolver recae en el Tribunal Constitucional Federal, ello en virtud del artículo 21.4 LFB.

\subsubsection{Marco legislativo básico}

Al margen de las previsiones constitucionales ya señaladas, el régimen jurídico de los partidos políticos ha sido objeto de desarrollo legislativo — tal y como ordena el artículo 21.5 LFB_ - viéndose este afectado por la reciente reforma constitucional que se acaba de mencionar. En efecto, la misma dio lugar a la aprobación de la Ley para la Exclusión de la Financiación de los Partidos contrarios a la Constitución — PartFinÄndG ${ }^{68}$ en virtud de la cual se han modificado, entre otras ${ }^{69}$, la Ley del Tribunal Constitucional Federal —BVerfGG_ y la Ley de Partidos — PartG_- en lo tocante a esa nueva posibilidad de privación de ayudas públicas a determinadas formaciones

65 Defendiendo incluso la suficiencia de una modificación por vía legislativa, EPPING, V., Eine Alternative zum Parteiverbot. Der Ausschluss von der staatlichen Parteienfinanzierung, op. cit., p. 33. En contra, en cambio, MORLOK, M., Parteienfinanzierung im demokratischen Rechtsstaat. Reformmöglichkeiten der Gewährung staatlicher Leistungen an politische Parteien, Friedrich Ebert Stiftung, Berlin, 2009.

66 BVerfGE, Urt. v. 17.1.2017 - 2 BvB 1/13, Rn. 625.

${ }^{67}$ Es de entender que la interpretación de estos conceptos jurídicos indeterminados es la misma que la realizada en el apartado anterior.

${ }^{68}$ Vigente desde el 29 de julio de 2017.

${ }^{69}$ Pues se han visto igualmente afectadas la Ley del Impuesto sobre la Renta -EstG_; el Decreto de Implementación del Impuesto sobre la Renta —EStDV_-, la Ley del Impuesto de Sociedades — KStG_- la Ley de sucesiones y donaciones — ErbStG_; y la Ley del Impuesto sobre el Valor Añadido -UstG-. 
políticas. Y por lo demás, son de igual aplicación en la materia la Ley Electoral —BWahlG_ — ${ }^{70}$; el Código Civil —BGB— ${ }^{71}$; y el Código Penal —StGB- ${ }^{72}$.

En cuanto al desarrollo legislativo de las previsiones constitucionales relativas a la declaración de inconstitucionalidad de un partido político —o de una parte del mismo ${ }^{73}$ — , esta implica su correspondiente disolución, así como la prohibición de creación de nuevas formaciones políticas sucesoras del partido excluido. De igual modo, y al margen de que lo anterior supone el fin de la financiación estatal ${ }^{74}$, cabe $^{2}$ la posibilidad de que el Tribunal Constitucional ordene el decomiso de su patrimonio para destinarlo a fines sociales o de interés general ${ }^{75}$. Y como efecto singular de la declaración de inconstitucionalidad, la Ley electoral establece la pérdida automática del escaño ${ }^{76}$, previsión esta que fue respaldada por el Tribunal Constitucional Federal pese a la prohibición del mandato imperativo prevista en el artículo $38 \mathrm{LFB}^{77}$. Respecto a su argumentación, el Alto Tribunal se fijó, de un lado, en el hecho de que, en la práctica, la conexión entre el partido político y sus representantes es tan intensa que estos actúan, en cierto modo, más como representantes del partido que de los ciudadanos. Y de otro, en que si la prohibición de partidos políticos tiene como finalidad impedir que determinadas ideas inconstitucionales sean empleadas para construir la voluntad política de la sociedad, es lógico excluir dichas ideas del Parlamento, centro por excelencia de la vida política ${ }^{78}$.

Refirámonos ahora a la posibilidad de adoptar medidas económicas contra aquellos partidos, o facciones dentro del mismo, declarados antidemocráticos pero no inconstitucionales por el Tribunal Constitucional Federal. En caso de que esa fuera la decisión acordada, y en virtud de las modificaciones introducidas en la Ley del Tribunal Constitucional Federal y en la Ley de Partidos vía reforma constitucional, dicho órgano podrá determinar la exclusión de la financiación estatal por un plazo de seis años, siendo este criterio extensible a aquellas formaciones que pretendiesen reemplazar a las sancionadas según el propio Tribunal. El momento en el cual dicha medida produce efectos será justo cuando la decisión en cuestión tenga lugar ${ }^{79}$.

${ }^{70}$ Por ejemplo, en relación con la pérdida del escaño parlamentario en el caso de prohibición del partido político al que se representa.

71 En relación con el procedimiento para la creación y afiliación a un partido político, aspectos a los que se les aplica el régimen general sobre asociaciones.

72 En materia de delitos y sanciones en el ejercicio de cargo público, así como sobre los delitos electorales.

73 Artículo 46.2 BVerfGG.

${ }^{74}$ Con efectos a partir del momento de la disolución, tal y como dispone el artículo 18.7 PartG.

75 Artículos 46 BVerfGG y 33 PartG.

76 Artículo 46.1.5 BWahlG, así como las leyes regionales sobre la materia.

77 Al respecto, KLEIN, Ein neues NPD-Verbotsverfabren? Rechtsprobleme beim Verbot politischer Parteien, op. cit., p. 7 a 9.

78 BVerfGE 2, 1 (72).

79 Artículos 46 a BVerfGG; y 18.7 PartG. Para más detalles sobre aspectos procesales de la disolución, ver LIMPERT, M., «Das rechtliche Ende politischer Parteien: Aufllösung und Verschmelzung», en Zeitschrift für Parlamentsfragen (ZParl), Heft 1/2009, pp. 140 y ss. 
En cuanto a la legitimación para instar la declaración de inconstitucionalidad y/o la exclusión de la financiación pública de un partido antidemocrático pero constitucional, recae en el Gobierno central, en el Bundestag y en el Bundesrat, así como en los Gobiernos regionales, si bien, en este último caso, solo respecto de los partidos cuya actividad se limite a ese ámbito. La solicitud de exclusión de financiación pública podrá presentarse de manera subsidiaria a la petición de declaración de la inconstitucionalidad de dicha formación — para todo lo anterior, artículo 43 BVerfGG_. Y en cuanto a la decisión final, que ya se ha dicho recae sobre el Tribunal Constitucional en exclusiva, deberá adoptarse por mayoría de dos tercios de la Sala competente -es decir, seis de ocho magistrados_-, en lugar de la mayoría simple —artículo 15.4 BVerfGG_-, muestra todo ello, de la singularidad del proceso de sanción sobre los partidos políticos en comparación con cualquier otra asociación ${ }^{80}$.

\section{LA ADAPTACIÓN JURISPRUDENCIAL ALEMANA AL TEST DE LA CONVENCIONALIDAD DEL TEDH: EL CASO DEL NPD}

\subsection{El criterio de la necesidad según la jurisprudencia del TEDH}

Como ya hemos tenido ocasión de señalar en otro momento, los artículos 10.2 y 11.2 CEDH enumeran cuáles son los tres requisitos que deberán respetarse a la hora de adoptar medidas restrictivas sobre la libertad de expresión y el derecho de asociación: la injerencia en cuestión ha de estar previamente contemplada por la ley; debe estar justificada para alcanzar fines legítimos, concretos y predeterminados; y ha de ser una medida necesaria en una sociedad democrática. En caso de superarse dicho test de la convencionalidad, no cabrá apreciar violación del CEDH.

Apuntado lo cual, y pese a que lo que realmente nos interesa al estudiar el asunto NPD es la última de las condiciones señaladas, creemos conveniente realizar un breve repaso a los rasgos principales que caracterizan cada una de ellas. Así, y respecto al primer requisito, sería incorrecto afirmar su existencia a partir del referido test exclusivamente, pues viene igualmente exigido por la necesidad de respeto a los principios de legalidad y seguridad jurídica ${ }^{81}$. Y sobre qué debe entenderse por «ley», el TEDH ha optado por una interpretación amplia, al considerar que dicho término hace referencia al Derecho vigente en un determinado sistema jurídico ${ }^{82}$. De igual

${ }^{80}$ MORLOK, «La prohibición de partidos políticos en Alemania», op. cit., p. 211.

81 IGLESIAS BÁREZ, «La ley de partidos políticos y el test de convencionalidad europeo. El diálogo entre el Tribunal Constitucional y el Tribunal Europeo de Derechos Humanos en torno a la ilegalización de Herri Batasuna y Batasuna», en Teoría y Realidad Constitucional, núm. 25, 2010, p. 572 .

82 CATALÀ I BAS, A. H., Libertad de expresión e información; la jurisprudencia del TEDH y su recepción por el Tribunal Constitucional: hacia un derecho europeo de los derechos humanos, Revista General del Derecho, Valencia, 2001, pp. 282 y ss. 
modo, es necesario que la norma sea pública, accesible y previsible en sus efectos ${ }^{83}$, si bien el Tribunal es consciente de la imposibilidad de proveer una certeza absoluta $^{84}$. En coherencia con ello, se considerará cumplida la primera de las tres condiciones contempladas en el CEDH cuando el ciudadano pueda prever razonablemente, en atención a las circunstancias, las consecuencias que una acción concreta pueda producir ${ }^{85}$. Por lo demás, apuntar el «escaso interés» del que goza dicho requisito en relación con la prohibición de partidos, pues el TEDH «ni siquiera exige que la norma en cuestión estuviera en una disposición escrita», siendo igualmente válida su previsión en una norma genérica, como pueda ser el caso de un precepto de la Constitución carente de desarrollo legislativo ${ }^{86}$.

En cuanto al segundo requisito, simplemente recordar que la injerencia debe encontrarse justificada por la persecución de un fin legítimo, concreto y determinado ${ }^{87}$. Esto no suele plantear grandes dificultades a los Estados pues, al tratarse de conceptos jurídicos indeterminados ${ }^{88}$, el margen de interpretación es muy amplio, con lo que es habitual que el TEDH dé por válidos los razonamientos proporcionados en tal sentido ${ }^{89}$. Por lo tanto, el momento de mayor trascendencia es aquel en el que el Tribunal procede a verificar la concurrencia o no del tercer requisito, esto es, si la limitación del derecho constituye una medida necesaria en una sociedad democrática ${ }^{90}$.

83 Entre otras, las SSTEDH de 4 de mayo de 2000, Asunto Rotaru contra Rumanía, párrafo 55; Asunto Maestri contra Italia, de 17 de febrero de 2004, párrafos 19 y ss.; Asunto Gaweda contra Polonia, de 14 de marzo de 2002, párrafo 39; y Asunto Haldimann y otros contra Suiza, de 24 de febrero de 2015, párrafo 36.

${ }^{84}$ STEDH de 25 de marzo de 1983, Asunto Silver y otros c. Reino Unido, párrafo 88.

85 SSTEDH de 26 de abril de 1979, Asunto The Sunday Times c. Reino Unido, párrafo 49; y de 2 de agosto de 1984, Asunto Malone c. Reino Unido, párrafo 66.

86 RODRÍGUEZ, A., «La declaración de inconstitucionalidad de Batasuna y la CEDH», en Montilla Martos, J. A. (ed.) La probibición de partidos políticos, Servicio de Publicaciones de la Universidad de Almería, Almería, 2004, p. 167.

${ }^{87}$ Como se nos recuerda en IGLESIAS BÁREZ, «La ley de partidos políticos y el test de convencionalidad europeo...», op. cit., p. 576, estamos ante «un requisito material, de justificación teleológica».

${ }^{88}$ Un intento de acotamiento del significado y alcance de los límites del artículo 10.2 CEDH se puede encontrar en BUSTOS GISBERT, R., «Los derechos de libre comunicación en una sociedad democrática», en García Roca, J. y Santolaya, P. (coords.) La Europa de los Derechos. El Convenio Europeo de Derechos Humanos, 2. a edición, Centro de Estudios Políticos y Constitucionales, Madrid, 2009, p. 613 y ss; y CATALÀ I BAS, Libertad de expresión e información. La jurisprudencia del TEDH ..., op. cit., p. 305 y ss. Ver igualmente, por ejemplo, las SSTEDH de 21 de enero de 1999, Asunto Janowski c. Polonia, párrafos 25 y 26; y de 20 de mayo de 1999, Asunto Rekvényi c. Hungría, párrafos 39, 40 y 41.

${ }^{89}$ CORCUERA, TAJADURA y VÍRGALA FORURIA, La ilegalización de partidos políticos..., op. cit., p. 294.

90 Ibid., y SAIZ ARNÁIZ, A., «La disolución de partidos políticos y el derecho de asociación: el test de convencionalidad, art. $11 \mathrm{CEDH»,} \mathrm{en} \mathrm{Actualidad} \mathrm{jurídica} \mathrm{Aranzadi,} \mathrm{n.}{ }^{\circ}$ 533, 2002, p. 4. 
Procedamos pues al estudio de esta última condición, recordando que, no existiendo democracia sin pluralismo ${ }^{91}$, a la hora de determinar si existe una necesidad en el sentido del artículo 11.2 CEDH, los Estados tienen un margen de apreciación limitado ${ }^{92}$. Esto es consecuencia de la rigurosidad de la supervisión llevada a cabo por el TEDH, más sí cabe en relación con los partidos políticos, ello en atención al rol esencial que estos desempeñan en una sociedad democrática ${ }^{93}$.

Partiendo de dicha premisa, de lo que se trata, en este tercer caso, es de determinar si la injerencia ha sido proporcionada, exigiéndose para ello la observación de dos subcondiciones ${ }^{94}$ : la primera, la existencia de una «necesidad social imperiosa», entendida como la existencia de un peligro potencial para el sistema democrático que justifique la adopción de la medida limitadora. Ello implica detenerse sobre las cuestiones relativas a «si existen indicios que muestren que el riesgo de daño a la democracia, siempre con la condición de que se acrediten, es suficiente y razonablemente próximo; y sobre si los actos y discursos constituyen un todo que da una imagen de un modelo de sociedad concebido y propugnado por el partido, y que estaría en contradicción con la concepción de una sociedad democrática ${ }^{95}$.

Y en cuanto a la segunda subcondición, se exige que la restricción sea proporcionada al fin legítimo perseguido, de manera que lo que se hace es «incluir de facto aquí también el examen de la proporcionalidad en sentido estricto, es decir, el equilibrio entre los beneficios y los sacrificios que comporta la medida restrictiva» ${ }^{96}$. La cuestión

91 Entre otras, las SSTEDH de 30 de enero de 1998, Asunto Partido Comunista Unificado de Turquía c. Turquía, párrafo 43; de 8 de diciembre de 1999, Asunto Partido de la Libertad y la Democracia c. Turquía (ÖZDEP) c. Turquía, párrafo 37; o de 30 de junio de 2009, Asunto Herri Batasuna y Batasuna c. España, párrafo 76.

92 Más sobre el margen de apreciación de los Estados en KASTANAS, E., Unité et diversité: Notions autonomes et marge d'appréciation des Etats dans la jurisprudence de la Cour européenne des droits de l'homme, Bruxelles, 1996; y GARCÍA ROCA, J., El margen de apreciación nacional en la interpretación del Convenio Europeo de Derechos Humanos: soberanía e integración, Civitas, Madrid, 2010.

93 Entre otras, las SSTEDH de 30 de enero de 1998, Asunto Partido Comunista Unificado de Turquía c. Turquía, párrafo 43; de 8 de diciembre de 1999, Asunto Partido de la Libertad y la Democracia c. Turquía (ÖZDEP) c. Turquía, párrafo 44; de 13 de febrero de 2003, Gran Sala, Asunto Partido de la Prosperidad y otros c. Turquía, párrafo 88; de 30 de junio de 2009, Asunto Herri Batasuna y Batasuna c. España, párrafo 77; o de 12 de abril de 2011, Asunto Partido Republicano de Rusia c. Rusia, párrafos 81 a 90 .

94 Ya desde las SSTEDH de 7 de diciembre de 1976, Asunto Handyside c. Reino Unido, párrafos 48 y 49; de 27 de marzo de 1996, Asunto Goodwin contra Reino Unido, párrafo 40; y Asunto Hertel contra Suiza, de 25 de agosto de 1998, párrafos 43 y ss.-

95 STEDH de 30 de junio de 2009, Asunto Herri Batasuna y Batasuna c. España, párrafo 83. En la misma línea, la STEDH de 13 de febrero de 2003, Gran Sala, Asunto Partido de la Prosperidad y otros $c$. Turquía, párrafo 110, donde se señala que el TEDH no puede criticar a los tribunales turcos por no haber actuado antes, a riesgo de intervenir prematuramente y antes de que el peligro en cuestión haya tomado forma y se haya convertido en realidad.

96 IGLESIAS BÁREZ, «La ley de partidos políticos y el test de convencionalidad europeo...», op. cit., p. 580. Por su parte, SAIZ ARNÁIZ, «La disolución de partidos políticos y el derecho de asociación: el test de convencionalidad, art. $11 \mathrm{CEDH»,} \mathrm{op.} \mathrm{cit.,} \mathrm{pp.} 4$ y 5, entiende «adecuado a la 
es ¿Qué elementos deben ser tenidos en cuenta a la hora de apreciar dicha proporcionalidad? Para el TEDH revisten trascendencia, en este sentido, la ideología del partido político plasmada en sus estatutos y en su programa electoral, sus actividades - como puedan ser las declaraciones públicas realizadas por sus dirigentes_-, las decisiones jurisdiccionales nacionales en relación con acciones penales emprendidas contra miembros del partido en relación con actividades políticas, o la existencia de terrorismo en el país y la vinculación con quienes lo practican por parte del partido político en cuestión ${ }^{97}$.

Y como colofón al examen sobre la necesidad de la medida, simplemente recordar lo ya apuntado en relación con los dos requisitos que el TEDH exige sean respetados por aquellos partidos que pretendan introducir modificaciones en la legislación o en las estructuras legales y constitucionales de un Estado: los medios empleados para llevar a cabo dicho plan deben ser legales y democráticos; y el cambio pretendido ha de ser compatible con los principios democráticos ${ }^{98}$.

\subsection{La potencialidad como sustituta del principio de proporcionalidad}

En su esencia, el principio de proporcionalidad o Verbältnismäßigkeitsprinzip ${ }^{99}$ prohíbe a los poderes públicos llevar a cabo actuaciones o intervenciones desmedidas - Übermassverbot_-, siendo el Tribunal Constitucional Federal el que lo ha convertido en un «principio constitucional de protección de los derechos fundamentales» ${ }^{100}$. A partir de ahí, la jurisprudencia del Alto Tribunal alemán ${ }^{101}$ ha fijado una serie de requisitos que deberán observarse en relación con cualquier intromisión de los poderes públicos en las libertades de los ciudadanos. Explicado de manera somera, toda injerencia:

propia jurisprudencia del TEDH hablar, pura y simplemente, de proporcionalidad (en sentido amplio, si se desea) como concepto que incluye tanto la necesidad social imperiosa de la restricción como su proporcionalidad «stricto sensu».

97 IGLESIAS BÁREZ, «La ley de partidos políticos y el test de convencionalidad europeo...», op. cit., p. 581.

98 Por ejemplo, las SSTEDH de 9 de abril de 2002, Asunto Yazar y otros c. Turquía, párrafo 49; de 13 de febrero de 2003, Gran Sala, Asunto Partido de la Prosperidad y otros c. Turquía, párrafo 98; y de 30 de junio de 2009, Asunto Herri Batasuna y Batasuna c. España, párrafo 79.

${ }^{99}$ Que ha sido adoptado por numerosos ordenamientos jurídicos nacionales europeos —España no es una excepción-, lógicamente cada uno con sus propias particularidades.

${ }^{100}$ Como señala ARNOLD, R., MARTÍNEZ ESTAY, J. I., y ZÚÑIGA URBINA, F., «El principio de proporcionalidad en la jurisprudencia del Tribunal Constitucional», en Estudios Constitucionales, Año 10, N. ${ }^{\circ} 1,2012$, pp. 68 y 69, aunque se aplica igualmente en otros ámbitos, «se trata esencialmente de un principio destinado a proteger los derechos y libertades, que si bien no está escrito, el TCF entiende que está implícito en los fundamentos del sistema constitucional alemán.

101 A raíz de la BVerfGE 7, 377. 
- Requiere de una finalidad legítima que la justifique.

— Exige una adecuación o idoneidad para la promoción — no necesariamente la realización- de dicho objetivo legítimo - Geeignetheit-.

- Ha de ser necesaria y, entre varias opciones de intervención, debe preferirse la menos gravosa para los derechos involucrados — mínimo de intervención-.

- Debe ser proporcional en sentido estricto, lo cual significa que la gravedad de la intromisión ha de ser adecuada al objeto de la intervención. Es decir, debe existir una proporción entre la magnitud de las intervenciones y la urgencia o necesidad de los objetivos ${ }^{102}$.

Vemos, por lo tanto, que no estando este principio de la proporcionalidad expresamente recogido, ni en la LFB ni en el CEDH, los criterios jurisdiccionales establecidos, tanto por el TEDH —en relación con el elemento de la necesidadcomo por el Tribunal Constitucional Federal, de cara a justificar una intromisión en los derechos fundamentales de la persona, guardan evidentes similitudes ${ }^{103}$. Sin embargo, el problema surgió cuando el Alto Tribunal alemán, que «emplea la Convención como ratio decidendi en sus sentencias y como instrumento de interpretación constitucional» ${ }^{104}$, negó la posibilidad de aplicación de dicho principio a lo establecido en el artículo 21.2 LFB, al recordar que esa opción «únicamente cabe si el organismo estatal interventor dispone de algún margen para la acción y la toma de decisiones». Si, por el contrario — continuó-, existe una obligación jurídica de adoptar una determinada medida — en este caso, la prohibición de un partido político- y no se habilitan opciones alternativas a ella con respecto al «si» — entendido como condicional o ponderación-y al «cómo», se descarta la aplicación del principio de proporcionalidad ${ }^{105}$.

102 ARNOLD, MARTÍNEZ ESTAY y ZÚÑIGA URBINA, «El principio de proporcionalidad en la jurisprudencia del Tribunal Constitucional», op. cit., pp. 71 y 72.

103 Si bien en HARTWIG, M., «La "proporcionalidad» en la jurisprudencia del Tribunal Constitucional Federal de Alemania», Von Bogdandy, A., Ferrer Mac-Gregor Poisot, E. y Morales Antoniazzi, M. (coords.) La justicia constitucional y su internacionalización ¿ Hacia un ius constitucionale commune en América Latina?. Tomo I, UNAM, México, 2010, p. 789, se nos recuerda que cuando más divergencias se observan entre ambos tribunales es en los casos de colisión entre derechos individuales, es decir, cuando no hay que ponderar el interés general con el individual —como ejemplos, las SSTEDH de 24 de junio de 2004, Asunto Von Hannover c. Alemania; y de 26 de mayo de 2004, Asunto Görgülü c. Alemania-.

104 TENORIO SÁNCHEZ, P. J., «La incorporación de la Convención Europea de los Derechos del Hombre a los ordenamientos internos», en Gómez Sánchez, Y. (coord.) Los derechos en Europa, UNED, 1997, pp. 162.

105 BVerfGE, Urt. v. 17.1.2017 - $2 \mathrm{BvB} 1 / 13$, Rn. 600. En el mismo apartado recuerda que fue el propio constituyente el que estableció, en relación con dicho precepto, que, «en el caso de las circunstancias de hecho, se debe determinar la inconstitucionalidad del partido. No hay margen para la toma de decisiones que permita la aplicabilidad del principio de proporcionalidad». Para afirmar eso el Alto Tribunal se apoyó en clásicos de la doctrina alemana como, entre otros, SEIFERT, K. H., 
Así las cosas, el Tribunal Constitucional Federal se vio ante la tesitura de elaborar una argumentación que, no consistiendo en la aplicación del principio de proporcionalidad, superase el test de convencionalidad antes explicado. Y lo hizo partiendo de la premisa de que una cosa es aplicar «el principio de proporcionalidad como un elemento de hecho no escrito» y, otra distinta, llevar a cabo una «interpretación de los elementos constitutivos individuales de la norma», lo cual incluye «tener en cuenta las garantías de libertad y las decisiones de valor contenidas en la norma básica» ${ }^{106}$.

El resultado de todo ello, la acuñación del principio de «potencialidad»o «Potentialität» por el Tribunal, criterio que no se aleja tanto del concepto de proporcionalidad si tenemos en cuenta que, en el fondo, la principal implicación consiste en que «la prohibición de estos partidos solo será proporcionada en relación con aquellos que potencialmente puedan causar una eliminación o alteración del orden fundamental libre y democrático» ${ }^{107}$. De esta forma, el Tribunal Constitucional Federal encontraba la manera de ajustarse a la doctrina del TEDH ${ }^{108}$, a la vez que, técnicamente hablando, «evitaba tener que rebajar sus propios criterios relativos a la prohibición de partidos» ${ }^{109}$. En cualquier caso, no deja de ser cierto que la introducción de ese elemento de la potencialidad implica, en la práctica, una cierta relajación del régimen de control de los partidos políticos en el ordenamiento jurídico alemán con respecto al criterio mantenido en relación con la prohibición de la KPD donde, como veremos en el siguiente apartado, para el Tribunal Constitucional Federal, aun sin mencionar expresamente la «potencialidad», era irrelevante si aquella formación tenía más o menos probabilidades de alcanzar sus objetivos antidemocráticos.

Die politischen Parteien im Recht der Bundesrepublik Deutschland, Heymanns, Köln, 1975, pp. 470 y ss.; y SCHMIDT, T., Die Freiheit verfassungswidriger Parteien und Vereinigungen, Duncker \& Humblot, Berlin, 1983, pp. 163 y ss.

${ }^{106}$ BVerfGE, Urt. v. 17.1.2017 - 2 BvB 1/13, Rn. 602.

107 KRÜPER, J., «Entscheidungsanmerkung», en Zeitschrift für das Juristische Studium, 3/2017, edición digital, consultada el 29 de diciembre de 2017, http://www.zjs-online.com/dat/ artikel/2017_3_1130.pdf, pp. 368 y 369.

${ }^{108}$ KRÜPER, «Entscheidungsanmerkung», op. cit., p. 369. Sobre las esperanzas de una sentencia armonizadora se pronunciaba ya INGOLD, A., Das Recht der Oppositionen, Mohr Siebeck, Tübingen, 2015, p. 504; apoyándose para ello, entre otros, en EMEK, S. D., «Parteiverbote und Europäische Menschenrechtskonvention, UTZ, München, 2006, p. 271; y MORLOK, M. «Politische Parteien», en Vesting, T. Y Korioth, S. (dirs.) Der Eigenwert des Verfassungsrecbts. Was bleibt von der Verfassung nach der Globalisierung?, Mohr Siebeck, Tübingen, 2011, p. 333.

109 Tal y como se pone de manifiesto en KRÜPER, «Entscheidungsanmerkung», op. cit., p. 369, que el nivel de protección de los derechos fundamentales en Alemania no pueda ser inferior al que ofrece el CEDH no significa que la estructura y las figuras legales de la jurisprudencia del TEDH tengan que ser exactamente reproducidos en su sistema jurídico. 


\subsection{Antidemocrático pero constitucional}

Pese a que la Alemania de la postguerra no tardó demasiado en decidirse por la exclusión del SRP y del KPD, lo cierto es que, desde entonces, esta medida no ha vuelto a ser implementada. Y no lo ha sido, ni siquiera, en relación con el NPD, partido político que, por sus características, parecía estar más cerca de padecer esa misma suerte ${ }^{110}$ en alguno de los dos procesos iniciados contra él. Partiendo pues de esta base, y habida cuenta de que el fracaso del primer procedimiento — finalizado en 2003 - se debió a la existencia de insalvables vicios en el mismo ${ }^{111}$ y no a cuestiones de fondo, nosotros nos detendremos en la Sentencia dictada por el Tribunal Constitucional Federal, el 17 de enero de 2017, pues contiene dos implicaciones de extraordinaria importancia para el estudio del régimen jurídico alemán aplicable a los partidos antidemocráticos: de un lado, el hecho de que, con su decisión, el Alto Tribunal ha enmendado su jurisprudencia anterior en la materia, homologándola a la doctrina del TEDH explicada en otro apartado anterior. Y de otro lado, la alusión que el Tribunal Constitucional Federal realiza a la capacidad del poder constituyente para configurar respuestas alternativas y graduales al margen de la prohibición, incluida la exclusión de la financiación pública ${ }^{112}$, lo que nos lleva a dedicar parte del apartado quinto a dicha cuestión.

Abordando en este punto, por lo tanto, solo el primer asunto, hay que comenzar por el recordatorio del Alto Tribunal alemán ${ }^{113}$ en el sentido de que, de cara a su prohibición, los partidos políticos deben carecer de control o influencia significativa por parte de las autoridades encargadas de la protección constitucional ${ }^{114}$. Posteriormen-

110 Como se nos recuerda en CORCUERA, TAJADURA y VÍRGALA FORURIA, $L a$ ilegalización de partidos políticos..., op. cit., p. 129, en 1993, y por primera vez desde 1951, el Gobierno federal y el Bundesrat interpusieron una demanda ante el Tribunal Constitucional Federal para instar la prohibición del Partido de los Trabajadores Liberales o Freibeitliche Deutsche Arbeiterpartei y del Lista Nacional o Nationale Liste. Sin embargo, ambas peticiones fueron rechazadas en 1993, al entender el Alto Tribunal que la débil estructura y la inexistencia de apoyo electoral de ambos grupos impedían su calificación como partidos políticos en el sentido de lo dispuesto en el artículo 21 LFB — tras lo cual, fueron el Gobierno federal y el regional de Hamburgo los que procedieron a su prohibición como asociaciones-.

111 Y es que, como quedó constatado en Sentencia del Tribunal Constitucional Federal, de 18 de marzo de 2003 -BVerfGE 107, 339-, existía un importante número de informadores policiales infiltrados en las altas esferas del partido, lo cual hacía dudar al tribunal de hasta qué punto las evidencias obtenidas contra dicha formación habían sido fabricadas o provocadas por los propios agentes. Más sobre esta cuestión en CORCUERA, TAJADURA y VÍRGALA FORURIA, La ilegalización de partidos políticos..., op. cit., pp. 129 a 136; LIMPERT, «Das rechtliche Ende politischer Parteien: Auflösung und Verschmelzung», op. cit., pp. 148 y 149; y MORLOK, «La prohibición de partidos políticos en Alemania», op. cit., p. 216 y ss.

112 BVerfGE, Urt. v. 17.1.2017 - 2 BvB 1/13, Rn. 527 y 625.

113 En clara alusión a lo sucedido en el primer proceso jurisdiccional contra el NPD. En este caso, en cambio, no se reprodujeron los problemas surgidos en aquel.

114 BVerfGE, Urt. v. 17.1.2017 - 2 BvB 1/13, Rn. 405. El organismo por excelencia en este ámbito lo constituye la Oficina Federal para la Protección de la Constitución —Bundesamt für Verfassungsschutz—, 
te añadió que, en materia de disolución de partidos políticos, el punto de partida del análisis debe situarse en los objetivos de aquel, así como en las conductas de sus seguidores $^{115}$, que solo podrán atribuirse a la formación en cuestión si existiera una influencia o aprobación de ese comportamiento por su parte ${ }^{116}$.

Dicho esto, la clave del asunto radica en la interpretación del término «tender $a{ }^{117}$ desvirtuar el orden fundamental libre y democrático, empleado en el artículo 21.2 LFB. Para delimitar su significado, el Tribunal Constitucional Federal comenzó recordando que la prohibición de partidos no es una vía para la mera prohibición de ideas, sino que es preciso que el partido político bajo sospecha vaya más allá de su compromiso con sus objetivos contrarios a la Constitución ${ }^{118}$. Y acto seguido, y esto es fundamental, entendió que no basta con que el partido defienda de manera activa y sistemática sus fines y actúe para socavar o abolir el orden básico libre y democrático —es lo que el Alto Tribunal denomina «actuación cualificada» o «qualifizirte Vorbereitung»— ${ }^{119}$. Es necesario, en adición, que existan indicadores específicos y de peso que hagan pensar, al menos, en la posibilidad de que dichas acciones, dirigidas contra los bienes protegidos en el artículo 21.2 LFB, tengan éxito ${ }^{120}$.

Vemos, por tanto, cómo el Alto Tribunal alemán se aparta del camino trazado en 1956, al resolver sobre el caso de la KPD. Y es que, si por aquel entonces se señalaba la posibilidad de declarar la inconstitucionalidad de un partido pese a la ausencia de perspectivas de materialización de sus objetivos inconstitucionales en el futuro ${ }^{121}$ -bastaba, por tanto, con que concurriera el elemento de la cualificación-, acabamos de comprobar que, al igual que sucede con la doctrina del TEDH sobre prohibición de partidos políticos, en la Alemania actual «los criterios de oportunidad prevalecen sobre los de legalidad» ${ }^{122}$.

agencia de inteligencia policial al servicio del Gobierno federal que se vio envuelta en la mencionada polémica relativa a las infiltraciones dentro del NPD, en el marco de la primera demanda para su prohibición.

115 BVerfGE, Urt. v. 17.1.2017 - 2 BvB 1/13, Rn. 557 y ss.

116 BVerfGE, Urt. v. 17.1.2017 - 2 BvB 1/13, Rn. 561 y ss.

117 Igualmente traducible como «buscar» o «perseguir». En alemán, «darauf ausgehen».

118 BVerfGE, Urt. v. 17.1.2017 - 2 BvB 1/13, Rn. 573. En alemán se habla de una «aktiv kämpferische, aggressive Haltung gegenüber der bestehenden Ordnung»- BverfGE 5, 85 (141); y BVerfGE, Urt. v. 17.1.2017 - 2 BvB 1/13, Rn. 574.

119 VerfGE, Urt. v. 17.1.2017 - 2 BvB 1/13, Rn. 574 y 577.

120 BVerfGE, Urt. v. 17.1.2017 - 2 BvB 1/13, Rn. 575 y ss.

${ }^{121}$ Como tampoco se descartaba la aplicación del artículo 21.2 LFB cuando, por ejemplo, un partido pospusiera la realización de sus objetivos inconstitucionales al no ver perspectivas de realización en un momento dado. Se añadía, en este sentido, que, «si la intención inconstitucional es comprobable, no es necesario esperar y ver si la situación política cambia y el partido realmente aborda la realización de sus objetivos inconstitucionales» —BVerfGE 5, 85 (143)—.

${ }^{122}$ Expresión que, siendo anterior a la Sentencia que aquí se analiza, fue empleada por CORCUERA, TAJADURA y VÍRGALA FORURIA, La ilegalización de partidos politicos..., op. cit., p. 315, para referirse únicamente al ámbito del Consejo de Europa. 
Sobre esa base, el Tribunal Constitucional Federal, pese a afirmar que el NPD tiene como objetivo la abolición del orden fundamental libre y democrático ${ }^{123}$, entendió incumplido el requisito de la potencialidad. En concreto porque, aunque declaró probado el compromiso adquirido por el partido con objetivos dirigidos a atentar contra dicho orden, y pese a concurrir ese elemento de la cualificación ${ }^{124}$, consideró que no existían indicios específicos y de peso que sugirieran que el NPD pudiera tener éxito en el logro de sus fines inconstitucionales ${ }^{125}$. La consecuencia de dicha deducción, la desestimación de la demanda por unanimidad de los miembros de la Sala, confirmándose así ese cambio jurisprudencial en relación con la relevancia jurisdiccional que se otorga al elemento de la capacidad de un partido para materializar sus proyectos antidemocráticos.

No queremos concluir este apartado sin realizar antes un breve comentario acerca de los factores que han podido incidir en esta modificación interpretativa del artículo 21.2 LFB. En ese sentido, es preciso tener en cuenta que el contexto histórico-político existente en 1956 era completamente distinto al actual y nos explicamos. En los años cincuenta, Alemania no representaba más que una joven democracia sujeta al control de las potencias aliadas, siendo además, aún vulnerable a las ideologías más extremistas, ya fueran de corte nacionalsocialista o comunista. Hoy el panorama es completamente distinto, en lo interno, por la consolidación de que gozan sus instituciones y por el escepticismo reinante frente al empleo de ese «arma de doble filo» ${ }^{126}$ que es la prohibición de partidos en la República Federal de Alemania ${ }^{127}$. Y en lo externo, por constituir dicho país uno de los sujetos de Derecho internacional

123 BVerfGE, Urt. v. 17.1.2017 - 2 BvB 1/13, Rn. 633. Entre las razones que el Tribunal esgrime para alcanzar dicha conclusión, son de destacar las siguientes, identificadas a partir de su programa político y de publicaciones y declaraciones llevadas a cabo por funcionarios del partido: 1. El concepto político de "pueblo» o "Volksgemeinschaft», contrario a la dignidad humana, al defender la segregación de los grupos sociales ajenos a la definición étnica que el partido realiza —extranjeros, migrantes, religiosos y otras minorías_, privándolos de sus derechos (BVerfGE, Urt. v. 17.1.2017 - 2 BvB 1/13, Rn. 634 a 757). 2. La abolición del vigente sistema de representación parlamentaria, abogando por la implantación de Estado basado en la primacía de la comunidad nacional — la aludida Volksgemeinschaft_étnicamente homogénea (BVerfGE, Urt. v. 17.1.2017 - 2 BvB 1/13, Rn. 758 a 804). 3. Su similitud con el nacionalsocialismo, dado su concepto de Volksgemeinschaft, su actitud antisemita y su menosprecio por el orden democrático existente. En este sentido, por ejemplo, su identificación proclamada con las principales personalidades del Partido Nacionalsocialista Obrero Español, el empleo de vocabulario, textos, canciones y símbolos nacionalsocialistas seleccionados, así como determinadas declaraciones revisionistas con respecto a la historia (BVerfGE, Urt. v. 17.1.2017 - 2 BvB 1/13, Rn. 805-843).

124 BVerfGE, Urt. v. 17.1.2017 - 2 BvB 1/13, Rn. 846-894.

125 BVerfGE, Urt. v. 17.1.2017 - 2 BvB 1/13, Rn. 896-1007.

126 BVerfGE, Urt. v. 17.1.2017 - 2 BvB 1/13, Rn. 405 y 586.

127 STOLLEIS, «Prohibición de partidos y exclusión política en la República de Bonn», op. cit., quien llega a hablar de un «trauma» causado por la prohibición del KPD, añadiendo que la nueva generación de magistrados del Tribunal Constitucional Federal ha llegado al compromiso de evitar, en la medida de lo posible, la prohibición de partidos políticos y la consiguiente aparición de «mártires» como consecuencia de este tipo de medida. En esa misma línea, KOMMERS, The Constitutional Jurisprudence of the Federal Republic of Germany, op. cit., p. 236, afirma la existencia en Alemania de un 
más poderosos y, por tanto, menos permeable ante corrientes antidemocráticas externas. Asimismo, nos parece indudable la influencia que la doctrina del TEDH - y el miedo al rechazo de una hipotética prohibición del $\mathrm{NPD}^{128}$ — ha ejercido para que algunos de los parámetros jurisprudenciales empleados hace ya más de sesenta años difieran de los actuales.

Entrando a valorar ahora el fondo del criterio seguido por el Tribunal Constitucional Federal, existen determinadas razones que nos llevan a adoptar una posición de cierta cautela sobre aquel, ello sin pretender ser, al mismo tiempo, tan pretenciosos como para aparentar dominar el contexto social, político y cultural alemán en que dicha decisión fue tomada. No lo hacemos, pero entendemos que ello no es óbice para, al menos, expresar nuestra inquietud sobre cómo la Sentencia relativa al NPD puede influir ahora que la extrema derecha parece revitalizarse en el país. Y no nos referimos al NPD, cuyos apoyos electorales se encuentran bajo mínimos ${ }^{129}$, sino a AfD que, tras las elecciones federales de septiembre de 2017, y con sus noventa y cuatro escaños y un 12,6\% de votos en el Bundestag, ha logrado, no solo que su presencia institucional supere por vez primera el ámbito regional, sino erigirse además en la tercera fuerza política del país.

Habida cuenta de ello, y frente al argumento que hace referencia al victimismo ${ }^{130}$ en que podría haber incurrido el NPD en caso de una hipotética prohibición ${ }^{131}$, a

aumento de la tolerancia hacia los discursos y actividades extremistas, desde finales de los años sesenta en adelante.

128 De la misma opinión, EPPING., Eine Alternative zum Parteiverbot. Der Ausschluss von der staatlichen Parteienfinanzierung, op. cit., p. 14; y KLEIN, Ein neues NPD-Verbotsverfabren? Rechtsprobleme beim Verbot politischer Parteien, op. cit., p. 20.

129 Teniendo en cuenta que, según el artículo 6.3 BWahlG, el porcentaje mínimo exigido para entrar en el Bundestag por la vía de los votos emitidos directamente al partido, o Zweistimme, es del $5 \%$ —en el sistema electoral alemán, en el que el ciudadano emite dos votos, aquel otro dirigido al candidato a representar a su circunscripción en el Bundestag recibe la denominación de Erststimme. Y como afirma VIDAL PRADO, C., «El sistema electoral alemán como modelo: ventajas e inconvenientes», en Asamblea: revista parlamentaria de la Asamblea de Madrid, n. ${ }^{\circ}$ 26, 2012, p. 221, «lo habitual es que los partidos minoritarios hagan una campaña electoral centrada en conseguir los segundos votos, los que van a ser decisivos a la hora de superar la barrera electoral del $5 \%$ y de conseguir el mayor número de escaños posibles según los criterios de reparto proporcionales»-, en las elecciones federales de 2009, el NPD no superó el 1,5\%, en las de 2013, descendió al 1,2\% de apoyos, y en 2017 no logró pasar del 0,4\%. Los datos oficiales completos se encuentran disponibles en https://www.bundeswahlleiter.de.

${ }_{130}$ STOLLEIS, «Prohibición de partidos y exclusión política en la República de Bonn», op. cit.

131 Amén de que la presencia de un grupo antidemocrático en la esfera pública puede servir para que continúe su propia desacreditación ante la sociedad —ello a través de sus actos cotidianos-; o de que, desde un punto de vista estratégico, puede resultar más inteligente permitir la actividad de esa formación en las instituciones públicas, lo cual facilita su seguimiento y control. Para un reciente e interesante estudio sobre la relación existente entre la prohibición de partidos y el incremento de la inestabilidad política, consúltese CASAL BÉRTOA, F. y BOURNE, A., «Prescribing democracy? Party proscription and party system stability in Germany, Spain and Turkey», en European Journal of Political Research, Vol. 56, Número 2, pp. 440-465. 
nosotros nos surgen las siguientes dudas: ¿No se estará enviando un mensaje confuso a la sociedad cuando se permite la presencia de partidos antidemocráticos y, al mismo tiempo, se recurre al concepto de democracia militante para afirmar que no todo vale en un Estado de derecho ${ }^{132} \mathrm{Y}$ si tenemos en cuenta que se permite la existencia de esos partidos mientras carezcan de opciones de alcanzar sus objetivos, de producirse en ellos un crecimiento súbito que llevase a su posterior prohibición, ¿No serían muchísimo mayores el victimismo y la dificultad para explicar esa pasividad inicial ante la opinión pública? ${ }^{133}$ Para nosotros, el peligro de decantarse por el empleo de criterios cuantitativos y no cualitativos es evidente ${ }^{134}$, por no hablar de que esta nueva categorización no deja de poner en duda la consideración de este tipo de formaciones como auténticos partidos políticos que pugnan por acceder a las instituciones públicas. Y es que se les permite la existencia con la condición de que carezcan del potencial suficiente para lograr ese objetivo para el que precisamente se constituye cualquier fuerza política.

A lo anterior hay que añadir, además, la probabilidad de que una decisión del Alto Tribunal alemán en sentido prohibitorio hubiera contado igualmente con el visto bueno del TEDH — aunque es cierto que con más dificultades, dada la especial protección que, como ya hemos señalado, otorga el CEDH a la libertad de expresión y al derecho de asociación-. En esa dirección se expresa el propio Tri-

132 Según PRANTL, «Das NPD-Urteil ist bedauerlich falsch», op. cit., se podría haber aprovechado para enviar el mensaje de que, sea mayor o menor su influencia en la sociedad, no existe espacio para partidos antidemocráticos en la Ley Fundamental de Bonn.

133 Y eso que, como ya señalamos en otro momento, en la STEDH de 13 de febrero de 2003, Gran Sala, Asunto Partido de la Prosperidad y otros c. Turquía, párrafo 110, el TEDH afirma no poder criticar a los tribunales turcos por no haber actuado antes, a riesgo de intervenir prematuramente y antes de que el peligro en cuestión hubiera tomado forma, convirtiéndose en realidad.

134 En contra del carácter decisivo que, como vemos, se le atribuye a la capacidad de un partido para alcanzar sus objetivos, entre otros, CORCUERA, TAJADURA y VÍRGALA FORURIA, La ilegalización de partidos políticos..., op. cit., p. 315; HINAJEROS PARGA, «La prohibición de partidos como mecanismo de defensa del Estado», op. cit., p. 474; HÖVER, B., Das Parteiverbot und seine rechtlichen Folgen, Bonn, 1975, p. 28; LOEWENSTEIN, «Militant Democracy and Fundamental Rights II», op. cit., pp. 638-658; y PRANTL, H., «Das NPD-Urteil ist bedauerlich falsch», en Süddeutschezeitung, edición digital, consultada el 3 de enero de 2018, http://www.sueddeutsche.de/politik/bundesverfassungsgerichtdas-npd-urteil-ist-bedauerlich-falsch-1.3336328. En el lado contrario, son de destacar las palabras de MEIER, H., «Zum Verbot der NPD fällt mir nichts mehr ein», en Meier, H. (dir.) Verbot der NPD-ein deutsches Staatsteather in zwei Akten, Berliner Wissenschafts-Verlag, Berlin, 2015, p. 102, al señalar que «la prohibición de un partido que no puede ser acusado de nada más allá de sus lemas, es de hecho innecesaria y legalmente cuestionable». Igualmente contrario a la prohibición del NPD, JESSE, E., «Verbieten oder Nichtverbieten? Zeitgenössische Beobachtungen aus fünf Jahrzenten», en Meier, H. (dir.) Verbot der NPD-ein deutsches Staatsteather in zwei Akten, Berliner Wissenschafts-Verlag, Berlin, 2015, pp. 259-267; KLEIN, Ein neues NPD-Verbotsverfahren? Rechtsprobleme beim Verbot politischer Parteien, Nomos, op. cit., p. 30; LICHDI, J., «Die rechtliche Bedeutung von Handlungen der NPD und ihrer Anhänger im Verbotsverfahren», en Lichdi, J., (dir.) Darf die NPD gegen Taten parteioser Neonazis verboten werden?, Weiterdenken-Heinrich-Böll-Stiftung Sachsen und der Amadeu-Antonio-Stiftung, 2016, p. 30; y OLGUN, U., «NPD-Verbot? Nein danke!», en Meier, H. (dir.) Verbot der NPD-ein deutsches Staatsteather in zwei Akten, Berliner Wissenschafts-Verlag, Berlin, 2015, pp. 254-258. 
bunal Constitucional Federal alemán, al manifestar que la prohibición del NPD soportaría un juicio «ampliado» de la necesidad en atención a diferentes factores. Por un lado, a su, cuando menos, falta de renuncia al uso de la violencia como medio de lucha política autodenominada como «revolucionaria»; su llamada a la exclusión de determinadas personas en atención a su condición étnica; y su condición de partido defensor del ideario nacionalsocialista y lo que ello implica para Alemania, todo lo cual impide hablar de una «organización política insignificante desde un punto de vista político» ${ }^{135}$. Y por otro lado, al hecho de que, en determinadas zonas del país, esta formación representa un «factor político extremadamente importante, definidor de la vida política y social en todos los niveles de las unidades territoriales democráticas por debajo del nivel federal» mientras que «a nivel nacional (...) opera como punto de contacto y oficina de enlace de las organizaciones extremistas de derecha» ${ }^{136}$.

Sea como fuere, la realidad es que, si no se procedió a la prohibición del NPD cuando gozaba de más apoyo popular ${ }^{137}$, no resulta extraña la decisión adoptada en enero de 2017 por el Tribunal Constitucional Federal, «cuyo verdadero significado reside en la redefinición de los requisitos de prohibición de cara a un futuro» ${ }^{138}$.

\section{PRINCIPALES OBSERVACIONES TRAS LA RECIENTE REFORMA CONSTITUCIONAL}

Como hemos tenido ya ocasión de comprobar, en el momento en el que el Tribunal Constitucional Federal hubo de hacer frente a la demanda de prohibición contra el NPD, la Constitución alemana no contemplaba más opción para los partidos antidemocráticos que la declaración o no de su inconstitucionalidad. Esto, sumado a la decisión de no prohibir su presencia en la vida pública, condujo en Alemania a la situación paradójica de tener que financiar con dinero público a partidos políticos que desprecian el mismo sistema democrático que les ayuda a subsistir.

135 Muy útil es aquí la opinión de BLIGH, G., Defending Democracy: A New Understanding of the Party-Banning Phenomenon, Vanderbilt Journal of Transnational Law, 46, p. 1372, al advertir que, cuando la prohibición tiene por objeto impedir la creación por el partido extremista de un clima de miedo o violencia, la aplicación de un test de probabilidad parece inútil pues el daño que se pretende evitar es difuso por naturaleza y difícil de definir. En adición, el autor afirma que casi cualquier partido cuya agenda incluya declaraciones de odio o se identifique con la violencia crea un peligro claro y presente, ello siempre que este no se refiera a un acto en particular sino que consista en la promoción de un clima de odio o violencia.

136 BVerfGE, Urt. v. 17.1.2017 - 2 BvB 1/13, Rn. 74.

137 Algo sobre lo que se pregunta MEIER, «Zum Verbot der NPD fällt mir nichts mehr ein», op. cit., pp. 102 y 103.

138 LICHDI, J., «Ein Urteil, das Spielraum lässt», en DIE ZEIT, edición digital, de 22 de junio de 2017, consultada el 4 de enero de 2018, http://www.zeit.de/politik/deutschland/2017-06/npdausschluss-parteienfinanzierung-bundestag. 
La reacción no se hizo esperar y, tal como se ha expuesto en otro momento, el Parlamento alemán procedió, pocos meses después, a la modificación del artículo 21 LFB para que los partidos políticos declarados antidemocráticos, pero no inconstitucionales, dejen de beneficiarse en un futuro de recursos económicos públicos y de ciertas ventajas fiscales —artículo 21.3 LFB_— ${ }^{139}$.

Habida cuenta de todo ello, varias son las observaciones que cabe realizar. La primera, en el sentido de que no está claro si será necesario iniciar un nuevo procedimiento ante el Tribunal Constitucional Federal de cara a excluir al NPD de dicha financiación; si, por el contrario, puede considerarse aún vigente la catalogación como «antidemocrático» que del partido hizo el Alto Tribunal alemán en enero de $2017^{140}$; o si, finalmente, nada de esto tendrá relevancia en un futuro próximo, puesto que el NPD va camino de desaparecer de las instituciones en los territorios en los cuales aún conserva un mínimo apoyo electoral. Sea como fuere, la realidad es que, a día de hoy, el partido político sigue contando con ayudas públicas a nivel regional y europeo, si bien estas se han visto ostensiblemente reducidas tras los malos resultados obtenidos por la formación política en las últimas elecciones federales, celebradas el 24 de septiembre de $2017^{141}$.

En cuanto a la segunda apreciación, y ligada al ámbito económico, se refiere a la constitucionalización de la excepción motivada al principio de igualdad de trato entre partidos ${ }^{142}$. Y ello porque, como hemos visto, en materia de ayudas públicas ya es posible establecer discriminaciones que van más allá de las estrictamente relacionadas con el respaldo electoral obtenido por cada formación política en unos comicios determinados ${ }^{143}$. Se distingue así, dentro de los partidos

139 Amén de los ya explicados cambios legislativos producto de la reforma constitucional.

${ }^{140}$ En DIE ZEIT, edición digital, de 22 de junio de 2017, consultada el 4 de enero de 2018, http:// www.zeit.de/politik/deutschland/2017-06/npd-ausschluss-parteienfinanzierung-bundestagbundesverfassungsgericht, el constitucionalista Christoph Möllers abogaba por actuar rápidamente y evitar así una transformación del NPD, lo cual podría llegar a exigir comenzar desde cero el proceso ante el Tribunal Constitucional.

141 Pues, al no alcanzar la barrera del 0,5\% — ya hemos dicho que se quedó en el 0,4 \%—, no tiene acceso a financiación en ese ámbito — mientras que en el año 2016, recibió alrededor de 1,14 millones de euros, según datos del Bundestag, obtenidos en https://www.bundestag.de/blob/503226/ eb02070236090c98b3ca24ce9dfc57fa/finanz_16-data.pdf_- Sin embargo, dichas ayudas le siguen siendo proporcionadas a nivel europeo y regional. En el primer caso porque, reproduciéndose la regla del $0,5 \%$ de cara a la obtención de ayudas, el partido logró un $1 \%$ de apoyos en las elecciones al Parlamento Europeo de 2014 - lo que le valió un escaño_; y, en el segundo, dado que ha logrado superar en distintos Länder el umbral del 1\% exigido de cara a la obtención de dicha financiación pública - para todos los supuestos explicados, artículo 18 PartG-.

142 Sobre el significado de este principio, EPPING, Eine Alternative zum Parteiverbot. Der Ausschluss von der staatlichen Parteienfinanzierung, op. cit., pp. 22 a 24; KISSLINGER, A., Das Recht auf politische Chancengleichbeit, Nomos, Baden-Baden, 1998; y MORLOK, M., «Dos cuestiones clave en la regulación jurídica de los partidos políticos: financiación y democracia interna», en Teoría y Realidad Constitucional, núm. 35, 2015, pp. 183-201.

${ }^{143}$ Una muestra de que ello no era posible, hasta entonces, la encontramos en la Sentencia del Tribunal Administrativo de Hesse, de 5 de abril de 2017. En ella, el Tribunal declaró que privar al NPD 
constitucionales, entre aquellos que persiguen objetivos acordes con la norma básica y quienes no lo hacen. En el primer caso, el Estado contribuirá económicamente para la defensa de sus ideales, siempre y cuando esa formación disfrute de apoyo social suficiente. En cambio, en el segundo, podrá negarse esa financiación pública, incluso cuando el número de adeptos sea superior al de otros partidos democráticos que sí se benefician de ella ${ }^{144}$. Nada impide, sin embargo, que estas formaciones antidemocráticas se sigan financiando mediante la percepción de donaciones privadas.

Como tercera observación, y aunque entendemos que habría sido más adecuado que ambas medidas hubieran sido incluidas en un mismo precepto — por ejemplo, en el propio artículo 21.2 LFB_- parece que ya puede hablarse de una aplicabilidad del principio de proporcionalidad en el marco del artículo 21 LFB, pues el Tribunal Constitucional dispone de la posibilidad de elegir entre varias medidas, dependiendo de las circunstancias concretas del caso $^{145}$.

Para finalizar, simplemente recordar que, pese a su indudable utilidad en ciertos casos, la lucha contra los enemigos de la democracia no puede fiarse exclusivamente a la introducción y aplicación de mecanismos jurídicos de protección del orden democrático, como si su simple existencia fuera a constituir la fórmula magistral para acabar con todo mal. De lo contrario, estaríamos incurriendo nuevamente en la conocida como «ilusión de los juristas», idea que parte de la convicción de que la caída de la República de Weimar se debió en exclusiva a la defectuosa regulación constitucional del momento, obviando la profunda crisis espiritual, económica, social e internacional por la que atravesaba el país en ese tiempo ${ }^{146}$.

de la financiación pública a la que tenía derecho, en virtud de los apoyos electorales obtenidos en la localidad de Büdingen, era contrario al principio de igualdad.

${ }^{144}$ Diferenciación que, para el profesor Michael Brenner, interviniente en la audiencia a seis expertos organizada por la Comisión de Asuntos Interiores del Bundestag, el 29 de mayo de 2017, previa a la reforma constitucional, se encuentra justificada en atención a las circunstancias concurrentes. Igualmente favorables a la exclusión financiera se declararon los profesores Martin Morlok, Uve Vollkmann, Christian Waldhoff y Christoph Möllers. Más escéptico se mostró, en cambio, el abogado Johannes Lichdi, al señalar que «una democracia dirigida por el Estado, en la que se favorecen o discriminan ciertos puntos de vista, contradice fundamentalmente el espíritu liberal de la Ley fundamental» — https://www.bundestag.de/dokumente/textarchiv/2017/kw22-pa-innenparteienfinanzierung/507396-.

145 Basándonos, para llevar a cabo esa afirmación, en las palabras pronunciadas por el Tribunal Constitucional Federal que, en atención a la redacción constitucional vigente en ese momento, descartó cualquier medida sancionadora que no consistiera en la prohibición de los partidos. A ello añadió que, en tanto el poder constituyente constituido no modificase la regulación, no habría espacio para la aplicación del principio de proporcionalidad en relación con el artículo 21.2 LFB-BVerfGE, Urt. v. 17.1.2017 - 2 BvB 1/13, Rn. 626-.

146 DE OTTO, Defensa de la Constitución y Partidos Políticos, op. cit., p. 56. 


\section{CONCLUSIONES}

I. Pese a que para la doctrina mayoritaria, el control ideológico de los partidos políticos exige la previa inclusión de cláusulas expresas de intangibilidad, en este trabajo se defiende la idea de una democracia material basada en la existencia de una serie de valores jurídicos esenciales sin los cuales no cabría hablar de Estado de derecho. Estos representan evidentes límites a la actividad e ideología de los partidos políticos, idea que es corroborada por el TEDH.

II. La declaración de inconstitucionalidad de partidos políticos contrarios al orden fundamental libre y democrático o a la existencia de la República Federal de Alemania —artículo 21.2 LFB - constituye uno de los diversos instrumentos de democracia militante previstos por la Constitución alemana de cara a la defensa del orden democrático.

III. La Sentencia del Tribunal Constitucional Federal alemán, dictada a principios de 2017 en respuesta a la demanda interpuesta contra el NPD, ha supuesto la adaptación de la jurisprudencia constitucional alemana a la doctrina del TEDH en materia de prohibición de partidos políticos. Es de destacar, en ese sentido, la acuñación del criterio de la «potencialidad» por el Tribunal alemán, erigiéndose el primero en elemento determinante a la hora de optar por la no exclusión de aquellas formaciones que, siendo abiertamente antidemocráticas, carezcan de capacidad para alcanzar sus objetivos. Esta decantación por los elementos cuantitativos, en detrimento de los cualitativos, ha dado lugar a la creación de una especie de categoría intermedia entre la prohibición y la libre participación en la lucha democrática, la cual no deja de poner en cuestión la consideración de este tipo de formaciones ccomo auténticos partidos políticos: se les permite la existencia con la condición de que carezcan de suficiente potencial como para lograr precisamente el fin para el que se constituye cualquier fuerza política.

IV. La reforma constitucional de julio de 2017 ha dado lugar a la redacción de un nuevo artículo 21.3 LFB, introduciéndose con él una opción alternativa a la declaración de inconstitucionalidad de los partidos. Desde entonces, el Tribunal Constitucional Federal podrá excluir de la financiación pública a aquellas formaciones que, persiguiendo objetivos antidemocráticos, no sean declaradas inconstitucionales en aplicación del mencionado test de la «potencialidad».

Esta novedad contiene importantes implicaciones en el sentido de que: primero, se ha constitucionalizado la excepción motivada al principio de igualdad de trato de los partidos políticos; y segundo, nada impide que ese tipo de formaciones siga recibiendo financiación privada por la vía de las donaciones de cara a su subsistencia.

V. En el resurgir de la ultra derecha en Alemania, con AfD como tercera fuerza en el Bundestag y con el NPD aún en ciertas instituciones públicas, el Estado alemán deberá permanecer vigilante y tener presente que, pese a su indudable utilidad en las 
situaciones más extremas, en la lucha contra los partidos antidemocráticos, la respuesta no puede pasar única y exclusivamente por la aplicación de mecanismos jurídicos de defensa del orden democrático.

\section{BIBLIOGRAFÍA}

Álvarez Conde, E. y Català i Bas, El derecho de partidos, 2. ${ }^{\text {a }}$ edición, Colex, Madrid, 2013.

Álvarez Conde, E. y Català i Bas, A., «La aplicación de la Ley Orgánica de Partidos Políticos. Crónica inacabada de la ilegalización de Herri Batasuna, Batasuna y Euskal Herritarrok», en Foro. Revista de Ciencias Jurídicas y Sociales. Nueva Época, núm. 00/2004, Universidad Complutense de Madrid, Madrid, 2004, pp. 7-35.

Alzaga Villaamil, O., «Hacia el estudio de lo preocupante en nuestro régimen de partidos», en Teoría y Realidad Constitucional, núm. 35, 2015, pp. 123-147.

Aragón Reyes, M., Constitución, Estado Constitucional, Partidos y Elecciones, y Fuentes del Derecho, VVAA, Tomo I, Aranzadi, Navarra, 2011.

ARnold, R., «La reforma constitucional en Alemania», en Revista de Derecho Político», núm. 37, 1992, pp. 373-384.

Arnold, R., Martínez Estay, J. I., y Zúñiga Urbina, F., «El principio de proporcionalidad en la jurisprudencia del Tribunal Constitucional», en Estudios Constitucionales, Año 10, N. ${ }^{\circ} 1,2012$, pp. 65-116.

BACHOF, O., Jueces y Constitución, Cuadernos Taurus, Madrid, 1963.

Bligh, G., Defending Democracy: A New Understanding of the Party-Banning Phenomenon, Vanderbilt Journal of Transnational Law, 46, pp. 1321-1379.

Bustos Gisbert, R., «Los derechos de libre comunicación en una sociedad democrática», en García Roca, J. y Santolaya, P. (coords.) La Europa de los Derechos. El Convenio Europeo de Derechos Humanos, 2. ${ }^{a}$ edición, Centro de Estudios Políticos y Constitucionales, Madrid, 2009, pp. 591-628.

Capoccia, G., «Militant Democracy: The Institutional Bases of Democratic Self-Preservation», en Annual Review of Law and Social Science, Vol. 9, 2013, pp. 207-226.

Casal Bértoa, F. y Bourne, A., «Prescribing democracy? Party proscription and party system stability in Germany, Spain and Turkey», en European Journal of Political Research, Vol. 56, Número 2, pp. 440-465.

CATAlà I BAs, A. H., Libertad de expresión e información; la jurisprudencia del TEDH y su recepción por el Tribunal Constitucional: hacia un derecho europeo de los derechos bumanos, Revista General del Derecho, Valencia, 2001.

Corcuera, J., Tajadura, J. y Vírgala Foruria, E., La ilegalización de partidos políticos en las democracias occidentales, Dykinson, Madrid, 2008.

De Esteban, J., y GonzÁlez-Trevijano, P. J., Tratado de Derecho Constitucional II, Universidad Complutense de Madrid, Madrid, 2004. 
De Otto Pardo, I., Defensa de la Constitución y Partidos Políticos, Centro de Estudios Constitucionales, Madrid, 1985.

De Vega, P., Legitimidad y representación en la crisis de la Democracia actual, Universidad Complutense de Madrid, 1998.

Denninger, E., «Democracia militante y defensa de la Constitución», en Benda, E., Maihofer, W., y Vogel, H. J. (dirs.) Manual de Derecho Constitucional, 2. edición, Marcial Pons, 2001, pp. 445-485.

EMEK, S. D., «Parteiverbote und Europäische Menschenrechtskonvention, UTZ, München, 2006, p. 271.

EpPING, V., Eine Alternative zum Parteiverbot. Der Ausschluss von der staatlichen Parteienfinanzierung, Nomos, Baden-Baden, 2013.

Fernández de Casadevante Mayordomo, P. «La prohibición de formaciones políticas como mecanismo de defensa del Estado y el debilitamiento de dicha protección tras las polémicas decisiones sobre Bildu y Sortu», en Revista Europea de Derechos Fundamentales, núm. 26, Editorial Comares, Madrid, 2015, pp. 111-137.

FERNÁNDEZ SARASOla, I., «Idea de partido y sistema de partidos en el constitucionalismo histórico español», en Teoría y Realidad Constitucional, núm. 7, 1. ${ }^{\circ}$ semestre, 2001, pp. 217-235.

FERnÁndeZ Vivas, Y., «El régimen de los partidos políticos en Alemania», en Teoría y Realidad Constitucional, núm. 31, 2013, pp. 457-502.

Forsthoff, E., «Die Umbildung des Verfassungsgesetzes», en Festschrift für Carl Schmitt, Duncker \& Humblot, Berlin, 1959.

García Roca, J., «Abuso de los derechos fundamentales y defensa de la democracia», en García. ${ }^{\circ}$ Roca, J., y Santolaya, P. (coords.) La Europa de los derechos. El Convenio Europeo de Derechos Humanos, Centro de Estudios Políticos y Constitucionales, Madrid, 2005, pp. 797-828.

- El margen de apreciación nacional en la interpretación del Convenio Europeo de Derechos Humanos: soberania e integración, Civitas, Madrid, 2010.

Gelberg, T. A., Das Parteiverbotsverfabren nach Art. 21 Abs. 2 GG am Beispiel des NPD-Verbotsverfabrens, V \& R Unipress, Göttingen, 2009.

Gómez Orfanel, G., «La defensa de la Democracia en la República de Weimar», en Morodo, R. y De Vega, P. (dirs.) Estudios de Teoría del Estado y Derecho Constitucional en honor a Pablo Lucas Verdú, Tomo I, Instituto de Investigaciones Jurídicas de la UNAM y Servicio de Publicaciones de la Facultad de Derecho UCM, México, 2011, pp. 327-246.

GómEZ SÁNCHEZ, Y., «El derecho de reunión y asociación», en Rovira Viñas, A. (coord.) Gobernanza democrática, Marcial Pons, Madrid, 2013, pp. 125-166.

Hartwig, M., «La «proporcionalidad» en la jurisprudencia del Tribunal Constitucional Federal de Alemania», Von Bogdandy, A., Ferrer Mac-Gregor Poisot, E. y Morales Antoniazzi, M. (coords.) La justicia constitucional y su internacionalización ¿Hacia un ius constitucionale commune en América Latina?, Tomo I, UNAM, México, pp. 781-791. 
Hinajeros Parga, A., «La prohibición de partidos como mecanismo de defensa del Estado», en Teoría y Realidad Constitucional, núms. 10-11, 2. ${ }^{\circ}$ semestre 2002-1er semestre 2003, UNED, Madrid, pp. 469-503.

Hollerbach, A., "Auflösung der rechtsstaatlichen Verfassung?», en Archiv des öffentlichen Rechts, núm. 85 (octubre 1960), pp. 241-270.

Höver, B., Das Parteiverbot und seine rechtlichen Folgen, Bonn, 1975.

IgLesias BÁREZ, M., «La Ley de partidos políticos y el test de convencionalidad europeo. El diálogo entre el Tribunal Constitucional y el Tribunal Europeo de Derechos Humanos en torno a la ilegalización de Herri Batasuna y Batasuna», en Teoría y Realidad Constitucional, núm. 25, UNED, Madrid, 2010, pp. 567-586.

IngOLD, A., Das Recht der Oppositionen, Mohr Siebeck, Tübingen, 2015.

IsEnseE, J., Würde des Menschen, en Handbuch der Grundrechte in Deutschland und Europa, Band IV, Müller, Heidelberg, 2011, pp. 3-136.

IssaCharrofF, S., «Fragile democracias», en Harvard Law Review, Vol. 120, Number 6, April 2007, p. 1409. pp. 1405-1467.

JEsse, E., «Verbieten oder Nichtverbieten? Zeitgenössische Beobachtungen aus fünf Jahrzenten», en Meier, H. (dir.) Verbot der NPD-ein deutsches Staatsteather in zwei Akten, Berliner Wissenschafts-Verlag, Berlin, 2015, pp. 259-267.

Jiménez CAmpo, J., "Algunos problemas de interpretación en torno al título X de la Constitución», en Revista del Departamento de Derecho Político, núm. 7, UNED, Madrid, 1980, pp. 81-105.

— «La intervención estatal del pluralismo», en Revista Española de Derecho Constitucional, núm. 1, Centro de Estudios Políticos y Constitucionales, 1981, pp. 161-184.

- «Sobre el régimen jurídico-constitucional de los partidos políticos», en Revista de Derecho Político, núm. 26, UNED, Madrid, 1988, pp. 9-26.

- Régimen jurídico de los partidos políticos y Constitución, Centro de Estudios Constitucionales, Madrid, 1994.

Kastanas, E., Unité et diversité: Notions autonomes et marge d'appréciation des Etats dans la jurisprudence de la Cour européenne des droits de l'bomme, Bruxelles, 1996.

Kelsen, H., Vom Wesen und Wert der Demokratie, 2. ${ }^{a}$ ed., Mohr, Tübingen, 1929.

- Esencia y valor de la democracia, Labor, Barcelona, 1934.

Kisslinger, A., Das Recht auf politische Chancengleichbeit, Nomos, Baden-Baden, 1998.

KLEIN, E., Ein neues NPD-Verbotsverfabren? Rechtsprobleme beim Verbot politischer Parteien, Nomos, Baden-Baden, 2012.

Kommers, D. P., The Constitutional Jurisprudence of the Federal Republic of Germany, 2. edición, Durham (Carolina del Norte), Duke University Press, 1997.

KRÜPER, J., «Entscheidungsanmerkung», en Zeitschrift für das Juristische Studium, 3/2017, edición digital, consultada el 29 de diciembre de 2017, http://www. zjs-online.com/dat/artikel/2017_3_1130.pdf, pp. 365-369.

Lasky, H. J., «Democracia», en Seligman E. R. A. (Ed.) Encyclopedia of the Social Sciences, vol. V, The Macmillan Company, 1959, New York. 
LICHDI, J., «Die rechtliche Bedeutung von Handlungen der NPD und ihrer Anhänger im Verbotsverfahren», en Lichdi, J., (dir.) Darf die NPD gegen Taten parteioser Neonazis verboten werden?, Weiterdenken-Heinrich-Böll-Stiftung Sachsen und der Amadeu-Antonio-Stiftung, 2016, p. 30

— «Ein Urteil, das Spielraum lässt», en DIE ZEIT, edición digital, de 22 de junio de 2017, http://www.zeit.de/politik/deutschland/2017-06/npd-ausschluss-parteienfinanzierung-bundestag.

Limpert, M., «Das rechtliche Ende politischer Parteien: Aufllösung und Verschmelzung», en Zeitschrift für Parlamentsfragen (ZParl), Heft 1/2009, pp. $140-154$.

Loewenstein, K., «Militant Democracy and Fundamental Rights II», en The American Political Sciences Review, vol. 31, núm. 4, Agosto 1937.

Lucas Verdú, P., Curso de Derecho Político, vol. II, Tecnos, Madrid, 1983.

MeIEr, H., Parteiverbote und demokratische Republik: Zur Interpretation und Kritik von art 21 abs 2 des Grund Gesetzes, Baden-Baden, 1993.

— «Zum Verbot der NPD fällt mir nichts mehr ein», en Meier, H. (dir.) Verbot $\operatorname{der}$ NPD-ein deutsches Staatsteather in zwei Akten, Berliner Wissenschafts-Verlag, Berlin, 2015, pp. 100-103.

— «Parteiverbote und «Streitbare Demokratie»-Einige Thesen», en Lichdi, J., (dir.) Darf die NPD gegen Taten parteioser Neonazis verboten werden?, Weiterdenken-Heinrich-Böll-Stiftung Sachsen und der Amadeu-Antonio-Stiftung, 2016, pp. 11-15.

Merino Merchán, J. F., Pérez-Ugena Coromina, M., y Vera Santos, J. M., Lecciones de Derecho Constitucional, Tecnos, 1997.

Morlok, M. «La regulación jurídica de la financiación de los partidos en Alemania», en Teoría y Realidad Constitucional, núm. 6, 2. ${ }^{\circ}$ semestre 2000, pp. 43-69.

- «La prohibición de partidos políticos en Alemania», en Montilla Martos, J. A. (ed.) La probibición de partidos políticos, Universidad de Almería, Almería, 2004, pp. 205-223.

- Parteienfinanzierung im demokratischen Rechtsstaat. Reformmöglichkeiten der Gewährung staatlicher Leistungen an politische Parteien, Friedrich Ebert Stiftung, Berlin, 2009.

— «Politische Parteien», en Vesting, T. Y Korioth, S. (dirs.) Der Eigenwert des Verfassungsrechts. Was bleibt von der Verfassung nach der Globalisierung?, Mohr Siebeck, Tübingen, 2011, p. 333-353.

- «Dos cuestiones clave en la regulación jurídica de los partidos políticos: financiación y democracia interna», en Teoría y Realidad Constitucional, núm. 35, 2015, pp. 183-201.

Nichelmann, R., Form und Funktion der «freibeitlichen demokratischen Grundordnung», Duncker \& Humblot, Berlin, 2013.

Popper, K., La sociedad abierta y sus enemigos, Barcelona, Paidós, 1991. 
PranTL, H., «Das NPD-Urteil ist bedauerlich falsch», en Süddeutschezeitung, edición digital, http://www.sueddeutsche.de/politik/bundesverfassungsgericht-das-npd-urteil-ist-bedauerlich-falsch-1.3336328.

Presno Linera, M. A., Los partidos y las distorsiones jurídicas de la democracia, Ariel, Barcelona, 2000.

Rensmann, T., «Procedural Fairness in a Militant Democracy: The «Uprising of the Decent» Fails Before the Federal Constitutional Court», en German Law Journal, vol. 4, núm. 11, 2003, pp. 1117-1136, edición digital, https://static1. squarespace.com/static/56330ad3e4b0733dcc0c8495/t/56b96e2122482e110fab1f34/1454992929978/GLJ_Vol_04_No_11_Rensmann.pdf.

Rodríguez, A., «La declaración de inconstitucionalidad de Batasuna y la CEDH», en Montilla Martos, J. A. (ed.) La probibición de partidos políticos, Servicio de $\mathrm{Pu}-$ blicaciones de la Universidad de Almería, Almería, 2004, pp. 165-184.

SAIZ Arnárz, A., «La disolución de partidos políticos y el derecho de asociación: el test de convencionalidad, art. $11 \mathrm{CEDH}$ », en Actualidad jurídica Aranzadi, n. ${ }^{\circ}$ 533, 2002, pp. 1-7.

Schmidt, T., Die Freibeit verfassungswidriger Parteien und Vereinigungen, Duncker \& Humblot, Berlin, 1983.

Schmiтt, C., Die geistesgeschichtliche Lage des heutigen Parlamentarismus, Duncker \& Humblot, München, 1923.

SEIfERT, K. H., Die politischen Parteien im Recht der Bundesrepublik Deutschland, Heymanns, Köln, 1975.

SiCHERT, M., «Das Parteiverbot in der wehrhaften Demokratie. Keine Toleranz gegenüber den Feinden der Toleranz!?», en Die Öffentliche Verwaltung 2001, S.671-681.

Solozabal Echavarria, J. J., «Sobre la constitucionalización de los partidos políticos en el Derecho Constitucional y en el ordenamiento español», en Revista de Estudios Políticos, núm. 45, mayo-junio, 1985, pp. 155 a 164.

Stern, K., Derecho del Estado de la República Federal Alemana, Madrid, Centro de Estudios Constitucionales, 1987.

Stolleis, M., «Prohibición de partidos y exclusión política en la República de Bonn», en la ponencia presentada con motivo del Seminario Internacional titulado Mecanismos de exclusión en la democracia de partidos, celebrado en la UNED, Madrid, el día 5 de abril de 2017, disponible online en https:/canal.uned.es/ $\mathrm{mmobj} /$ index/id/56114.

— «La justicia política en Alemania occidental», en Gutiérrez Gutiérrez, Ignacio (coord.) Mecanismos de exclusión en la democracia de partidos, Marcial Pons, Madrid, 2017.

TENORIO SÁNCHEZ, P. J., «La incorporación de la Convención Europea de los Derechos del Hombre a los ordenamientos internos», en Gómez Sánchez, Y. (coord.) Los derechos en Europa, UNED, 1997, pp. 153-170.

- Constitución, derechos fundamentales y seguridad. Panorama comparativo, Civitas, Madrid, 2010, p. 125. 
Torres del Moral, A., «La inconstitucionalidad de los partidos. A propósito de la Ley 6/2002 de Partidos Políticos», en Revista de Derecho Político, núm. 60, UNED, Madrid, 2004, pp. 41-71.

- «Democracia militante», en VVAA Derecho Constitucional para el siglo XXI, Tomo I, Thomson-Aranzadi, Navarra, 2006, pp. 209-224.

— «Terrorismo y principio democrático», en Revista de derecho político, N. ${ }^{\circ} 78$, mayo-diciembre 2010, pp. 95-160.

VIDAl Prado, C., «El derecho de participación política y la representación», en Revista Facultad de Derecho y Ciencias Políticas, N. ${ }^{\circ}$ 96, 1996, pp. 81-115.

— «El sistema electoral alemán como modelo: ventajas e inconvenientes», en Asamblea: revista parlamentaria de la Asamblea de Madrid, n. ${ }^{\circ}$ 26, 2012, pp. 217-234.

ZIEkofF, J., «Vereinigungsfreiheit», en Handbuch der Grundrechte in Deutschland und Europa, Band IV, Müller, Heidelberg, 2011, p. 1213-1248.

Title:

The prohibition on political parties in Germany. The new criterion of potentiality and the recent constitutional reform for not funding anti-democratic but constitutional formations: special attention to the case of the NPD.

\section{Summary.}

1. Introduction. 2. The right of every democratic system to its self-defence. 2.1. Theoretical approach. 2.2. Express intangibility clauses and ideological control. 3. The defense of democracy and political parties in the German legal system. 3.1. The German concept of militant democracy. 3.2. Legal regime applicable to anti-democratic political parties. 3.2.1. Constitutional framework. 3.2.2. Basic legislative framework. 4. The German jurisprudential adaptation to the ECHR conventionality control: the NPD case. 4.1. The necessity test according to the ECHR jurisprudence. 4.2. Potentiality as a substitute for the principle of proportionality. 4.3. Anti-democratic but constitutional. 5. Main observations after the recent constitutional reform. 6. Conclusions. Bibliography.

\section{Resumen:}

El año 2017 fue testigo de importantes acontecimientos en relación con el fenómeno de la ideología de ultra derecha en Alemania. Si en enero, el Tribunal Constitucional Federal fallaba en contra de la prohibición del 
NPD pese a reconocer el carácter antidemocrático de sus objetivos, en julio entraba en vigor una reforma constitucional para excluir de la financiación estatal a formaciones políticas que, siendo contrarias al orden democrático, no sean objeto de prohibición al carecer del potencial necesario para alcanzar sus objetivos. A modo de colofón, septiembre finalizaba con la celebración de elecciones federales y la entrada de la AfD en el Bundestag como tercera fuerza política. A la luz de todo ello, en el presente trabajo se apuesta por el análisis de las principales implicaciones jurídicas derivadas de dichos hechos, ello con el ánimo de ofrecer al lector una visión actualizada sobre el control jurídico aplicable a la ideología de los partidos políticos en Alemania.

\begin{abstract}
:
2017 witnessed important events in relation to the phenomenon of the right-wing ideology in Germany. First, in January, the Federal Constitutional Court ruled against the prohibition of the NPD, despite recognizing the anti-democratic nature of its objectives; then, in July, a constitutional reform came into effect to exclude from the state funding those political formations that, contravening the democratic order, are not prohibited as they lack the necessary potential to achieve their objectives. To conclude, September ended with the holding of federal elections and the entry of the AfD into the Bundestag, as the country's third largest force. In light of all this, the present work is committed to the analysis of the main legal implications derived from these events, this with the aim to offer the reader an updated view on the legal control applicable to the ideology of political parties in Germany.
\end{abstract}

\title{
Palabras clave:
}

Alemania, partidos políticos, prohibición, reforma constitucional, no financiación.

\section{Key words:}

Germany, political parties, prohibition, constitucional reform, non financiation. 